\title{
Les Sarthois, leur presse et l'Asie (de l'Inde à l'Extrême-Orient) entre 1844 et la veille de la Première Guerre mondiale
}

\section{Pierre Foucault}

\section{(2) OpenEdition \\ Journals}

Édition électronique

URL : http://journals.openedition.org/abpo/1126

DOI : $10.4000 /$ abpo. 1126

ISBN : 978-2-7535-1499-7

ISSN : 2108-6443

Éditeur

Presses universitaires de Rennes

Édition imprimée

Date de publication : 20 septembre 2005

Pagination : 143-174

ISBN : 978-2-7535-0201-7

ISSN : 0399-0826

\section{Référence électronique}

Pierre Foucault, « Les Sarthois, leur presse et l'Asie (de l'Inde à l'Extrême-Orient) entre 1844 et la veille de la Première Guerre mondiale ", Annales de Bretagne et des Pays de l'Ouest [En ligne], 112-3 | 2005, mis en ligne le 20 septembre 2007, consulté le 02 mai 2019. URL : http://journals.openedition.org/ abpo/1126; DOI : 10.4000/abpo.1126 


\title{
Les Sarthois, leur presse et l'Asie (de l'Inde à l'Extrême-Orient) entre 1844 et la veille de la Première Guerre mondiale
}

\author{
Pierre FoucAulT $\dagger$ \\ Maître de conférences en histoire contemporaine, \\ LHAMANS - Université du Maine
}

C'est apparemment un rapprochement bizarre qui est proposé ici. Comment et pourquoi, en effet, confinés dans leurs horizons bocagers, les Sarthois s'intéresseraient-ils à ces mondes si lointains et si différents du leur, au XIX ${ }^{\mathrm{e}}$ siècle?

En fait, comme un grand nombre de leurs compatriotes à cette époque, ils se montrent soucieux de grandeur nationale. Or, après la guerre de l'opium, les Français ont obtenu dans le sillage des britanniques, par le Traité de Whampoa du 24 octobre 1844, des droits commerciaux et un protectorat sur les missionnaires et fidèles catholiques de l'Empire Chinois ${ }^{1}$. L'Asie reprend une place de choix dans la compétition qui mobilise progressivement l'ensemble des puissances européennes en mal de domination mondiale. Pour les catholiques les plus fervents, le souci de la conversion des peuples païens, porté par un important réveil missionnaire ${ }^{2}$, s'ajoute à la préoccupation patriotique; le continent asiatique au sein duquel opèrent nombre d'apôtres venus de notre région, représente évidemment pour eux, une terre au profit de laquelle ils peuvent mobiliser leur zèle ${ }^{3}$.

1. FAIRBANK, John K., La Grande Révolution Chinoise (1800-1989), Paris, Flammarion, coll. "Champs ", 1997, 550 p.

2. Pour l'évoquer, contentons-nous de rappeler la création à Lyon de l'œuvre de la Propagation de la Foi, en 1822. Le diocèse du Mans où elle s'implante dès l'année suivante figure, en 1824 , au $9^{\mathrm{e}}$ rang des donateurs. À noter également que l'instruction "Neminem Profecto " du Pape Grégoire XVI, qui dessine les grandes lignes de l'action de l'Église catholique dans les pays de mission à l'aube de l'époque contemporaine, datée du 23 novembre 1845 .

3. Entre 1801 et le début du xxe siècle, 38 missionnaires sarthois sont partis vers le vaste domaine qui s'étend de l'Inde, à la Chine et au Japon; leurs voisins mayennais, avec lesquels ils ont partagé un destin religieux commun, au sein d'un unique diocèse jusqu'en 
Quelle image les Sarthois se font-ils des pays qui s'étendent de l'Inde jusqu'aux extrémités orientales du continent asiatique et de leurs populations? Quelle place occupent-ils dans leur esprit et dans leur vie?

Loin d'ignorer l'importance que revêtent les revues et journaux nationaux, les bulletins répandus pour soutenir l'action missionnaire ${ }^{4}$ ou les ouvrages disponibles dans les bibliothèques publiques locales ${ }^{5}$, pour la diffusion d'informations et de connaissances sur l'Asie, nous avons pris, ici, le parti de limiter l'observation à la presse locale (devenue progressivement accessible au plus grand nombre), pour mesurer la place accordée à ces pays, appréhender les images qu'elle en donne (souvent, du reste, à partir d'emprunts à des titres nationaux), percevoir ainsi une éventuelle intégration de réalités asiatiques dans la vie quotidienne des Sarthois; ceci, depuis la première ouverture de la Chine aux intérêts français (pour ce qui est du XIX ${ }^{\mathrm{e}}$ siècle) dans le cadre du Traité de 1844, jusqu'à la veille de la Première Guerre mondiale, c'est-à-dire au cours d'une période qui voit se développer les efforts européens pour prendre le contrôle de ce continent et en exploiter les potentialités.

\section{La place accordée à l'Inde et à l'Extrême-Orient dans la presse sarthoise}

\section{Une place modeste, mesurée à l'aulne des intérêts nationaux}

Cette approche est effectuée à partir de sondages ${ }^{6}$ qui croisent deux types de préoccupations : d'une par la diversité des opinions politiques des journaux disponibles, de l'autre l'existence d'évènements susceptibles de placer l'Asie au premier rang de l'actualité. Le tableau suivant permet d'en donner les clés et d'en dégager les constatations quantitatives.

On y observe la modestie de la place accordée à l'Asie du Sud et de l'Est dans la presse locale.

1855, ne sont pas en reste, avec au minimum une soixantaine de représentants dans la même zone (selon les archives diocésaines et les Semaines religieuses du Mans et de Laval). La presse locale bien pensante attire indistinctement l'attention des lecteurs sur l'activité des uns et des autres.

4. Les Annales de la Propagation de la Foi et les bulletins de La Sainte Enfance se rencontrent très fréquemment sur les rayonnages des bibliothèques sans influence catholique.

5. Le continent asiatique n'occupe qu'une place secondaire dans les bibliothèques dont nous possédons les inventaires. Ainsi, la bibliothèque populaire de la Sarthe ne propose-t-elle que 8 titres sur l'Inde ou l'Extrême-Orient parmi 924 ouvrages $(0,8 \%)$ en 1866 et la bibliothèque paroissiale de La Couture, 24 sur 3560 volumes $(0,7 \%)$ en 1873 ; la bibliothèque populaire de La Flèche (avec 23 livres sur 1840, soit 1,25 \% de son fonds, en 1900) fait un peu mieux, mais il s'agit d'une autre époque et de La Flèche dont certains habitants peuvent avoir des raisons spécifiques de s'intéresser à l'Asie.

6. Contrairement aux autres titres, La Semaine du Fidèle a fait l'objet d'un dépouillement systématique. 


\begin{tabular}{|c|c|c|c|c|c|}
\hline $\begin{array}{l}\text { Titre du Journal } \\
\text { et périodicité* }\end{array}$ & $\begin{array}{c}\text { Option } \\
\text { politique }^{* *}\end{array}$ & \begin{tabular}{|c|} 
Limites \\
du sondage
\end{tabular} & $\begin{array}{l}\text { Justification de } \\
\text { ce choix }\end{array}$ & $\begin{array}{c}\text { Nombre } \\
\text { d'articles }\end{array}$ & $\underset{* * *}{\text { Indice }}$ \\
\hline $\begin{array}{l}\text { Le Courrier } \\
\text { de la Sarthe }(\mathrm{T}-\mathrm{H})\end{array}$ & $\begin{array}{c}\text { Li. } \\
\text { Puis R. }\end{array}$ & $\begin{array}{l}6 / 1844- \\
5 / 1845\end{array}$ & Traité de Whampoa & 8 & 0,05 \\
\hline L'Union $(\mathrm{T}-\mathrm{H})$ & $\mathrm{M}$ & année 1858 & \begin{tabular}{|c} 
- Révolte des Cipayes \\
- Intervention française \\
en Chine
\end{tabular} & 82 & 0,52 \\
\hline $\begin{array}{l}\text { La Chronique } \\
\text { de l'Ouest }(\mathrm{T}-\mathrm{H})\end{array}$ & Lé & \begin{tabular}{|} 
années 1859 \\
à 1861 \\
année 1867 \\
année 1968
\end{tabular} & $\begin{array}{c}\text { - Suite de l'intervention } \\
\text { en Chine, en Indochine } \\
\text { - Martyr du sarthois } \\
\text { Berneux en Corée } \\
\text { - Début de l'ère Meiji } \\
\text { au Japon } \\
\end{array}$ & $\begin{array}{c}104 \\
8 \\
23\end{array}$ & $\begin{array}{l}0,22 \\
0,05 \\
0,14\end{array}$ \\
\hline $\begin{array}{l}\text { L'Avenir (Q) } \\
\text { La Chronique } \\
\text { de l'Ouest (Q) }\end{array}$ & $\begin{array}{l}\mathrm{R} \\
\text { Lé }\end{array}$ & \begin{tabular}{|c|} 
année 1877 \\
1 à $6 / 1878$ \\
1 à $6 / 1878$
\end{tabular} & Grave famine en Asie & $\begin{array}{c}5 \\
11 \\
6\end{array}$ & $\begin{array}{l}0,01 \\
0,07 \\
0,03\end{array}$ \\
\hline $\begin{array}{l}\text { L'Avenir (Q) } \\
\text { La Chronique } \\
\text { de l'Ouest (Q) } \\
\text { L'Union (Q) } \\
\text { L'Union } \\
\text { Républicaine (Q) }\end{array}$ & $\begin{array}{l}\text { R } \\
\text { Lé } \\
\text { M } \\
\text { RO }\end{array}$ & $\begin{array}{l}7 \text { à } 12 / 1883 \\
3 \text { et } 4 / 1884 \\
2 \text { et } 3 / 1885 \\
3 \text { et } 4 / 1885\end{array}$ & $\begin{array}{c}\text { Conquête Française } \\
\text { de Tonkin }\end{array}$ & $\begin{array}{l}51 \\
39 \\
\\
25 \\
32\end{array}$ & $\begin{array}{l}0,32 \\
0,72 \\
\\
0,50 \\
0,61\end{array}$ \\
\hline $\begin{array}{l}\text { L'Avenir } \\
\text { de la Sarthe (Q) }\end{array}$ & $\mathrm{R}$ & $\begin{array}{l}\text { année } 1889 \\
7 \text { à } 12 / 1894 \\
1 \text { à } 6 / 1895\end{array}$ & $\begin{array}{c}\text { - Exposition universelle } \\
\text { de Paris } \\
\text { - Guerre } \\
\text { Sino-japonaise } \\
\end{array}$ & $\begin{array}{r}22 \\
168\end{array}$ & $\begin{array}{l}0,07 \\
0,53\end{array}$ \\
\hline $\begin{array}{l}\text { La Sarthe }(\mathrm{Q}) \\
\text { Le Petit Manceau (Q) }\end{array}$ & $\begin{array}{c}\mathrm{N} \\
\mathrm{Rad}\end{array}$ & $\begin{array}{l}\text { année } 1900 \\
\text { année } 1900\end{array}$ & $\begin{array}{l}\text { Révolte des Boxers } \\
\text { en Chine }\end{array}$ & $\begin{array}{c}124 \\
98\end{array}$ & $\begin{array}{l}0,39 \\
0,62\end{array}$ \\
\hline La Sarthe $(\mathrm{Q})$ & $\mathrm{N}$ & $\begin{array}{l}1 \text { à } 6 / 1904 \\
1 \text { à } 6 / 1905 \\
\end{array}$ & Guerre Russo-Japonaise & 58 & 0,18 \\
\hline Le Petit Manceau (Q) & Rad & \begin{tabular}{|c|} 
année 1910 \\
$9 / 1911$ et \\
$2 / 1912$
\end{tabular} & $\begin{array}{l}\text { - Troubles en Chine } \\
\text { et Indochine } \\
\text { - Révolution Chinoise }\end{array}$ & $\begin{array}{c}7 \\
28\end{array}$ & $\begin{array}{l}0,02 \\
0,18\end{array}$ \\
\hline
\end{tabular}

* T-H : tri-hebdomadaire; Q : quotidien

** Li : libéral; Lé : légitimiste; M. : monarchiste; $\mathrm{N}$ : nationaliste; R : républicain; RO : républicain opportuniste; Rad : radical

*** L'indice est calculé de manière simpliste : il résulte de la division du nombre d'articles relevés touchant les pays asiatiques, par le nombre de numéros publiés pendant la période du sondage, en dehors de toute considération de place ou de surface occupée dans le journal.

La situation ne s'améliore de façon significative que lorsque se produisent des évènements qui impliquent directement la France ou ses ressortissants, mais à l'évidence, l'importance du Traité de 1844 qui ouvre la Chine aux influences françaises n'a pas été perçue. Par contre, l'expédition militaire franco-britannique qui aboutit à la prise de Pékin en 1860, la conquête de Tonkin qui tient l'opinion en haleine durant plusieurs années ou la révolte des Boxers, objet d'une curiosité morbide autour du sort des européens et des catholiques indigènes assiégés dans les légations de Pékin, en 1900, font l'objet de nombreux articles (le rythme s'établit alors à un " papier " sur le sujet dans environ un numéro sur deux).

L'implication des puissances européennes rivales dans les évènements qui secouent l'Asie paraît une autre bonne raison de lui accorder un peu plus de place dans l'information. Les difficultés britanniques en Inde sont 
ainsi observées avec attention et non sans satisfaction lors de la révolte des Cipayes en 1858. La guerre sino-japonaise de 1894-1895, occasion de démontrer la supériorité française sur les allemands qui ont conseillé et armé les chinois tandis que le " petit " Japon nous a plutôt fait confiance, fournit la matière à des développements réguliers assez considérables. La moindre densité de l'information, constatée lors de la confrontation russojaponaise en 1904-1905 paraît surtout résulter de l'enlisement d'un conflit qui, après avoir suscité, à ses débuts, l'intérêt de la presse et de ses lecteurs, finit par les fatiguer, à moins qu'il s'agisse de ne pas s'appesantir sur certaines conclusions désagréables au sujet de notre grand allié russe.

À l'opposé, les événements qui semblent ne concerner que les populations asiatiques retiennent peu l'attention; il en est ainsi de l'ouverture de l'ère Meiji en 1868 ou des troubles annonciateurs de la révolution chinoise au début du $\mathrm{XX}^{\mathrm{e}}$ siècle, pour ne rien dire de l'indifférence presque totale face à la famine terrible qui dévaste le continent à la fin des années 1870 ou aux effets des catastrophes naturelles périodiques.

\section{La Semaine du Fidèle : des préoccupations spécifiques}

Du 29 novembre 1862, jour de la parution de son premier numéro, au 31 décembre 1914 (fin de la période d'observation), La Semaine du Fidèle, modeste hebdomadaire d'information religieuse de l'Évêché du Mans, compte 2709 numéros. L'ensemble des articles consacrés à l'Inde et à l'Extrême-Orient s'y élève à 348, soit un tous les deux mois environ (ce qui représente un rapport de 0,12 ). Leur fréquence est loin d'être toujours la même comme le montre le tableau suivant.

\begin{tabular}{|c|c|c|c|}
\hline Période considérée & $\begin{array}{c}\text { Nombre d'articles } \\
\text { impliquant l'Inde } \\
\text { ou les pays } \\
\text { d'Extrême-Orient }\end{array}$ & $\begin{array}{c}\text { \% par rapport aux } \\
\text { numéros publiés } \\
\text { au cours } \\
\text { de la période }\end{array}$ & $\begin{array}{c}\text { Nombre de mission- } \\
\text { naires sarthois } \\
\text { et « assimilés " } \\
\text { opérant dans la zone }\end{array}$ \\
\hline $1862-1870$ & 57 & 0,13 & 17 \\
$1871-1880$ & 121 & 0,23 & 25 \\
$1881-1890$ & 79 & 0,15 & 17 \\
$1891-1900$ & 52 & 0,10 & 17 \\
$1901-1910$ & 38 & 0,07 & 2 \\
$1911-1914$ & 1 & 0,004 & $(43)^{*}$ \\
Ensemble de & 348 & 0,12 & \\
1862 à 1914 & & & \\
\hline
\end{tabular}

* Ce chiffre n'est pas le résultat d'une addition. Certains missionnaires vivent en Asie durant plusieurs décennies.

Comme dans le reste de la presse locale, on constate, dans La Semaine du Fidèle, des variations importantes dans l'attention accordée à l'Asie. Dans ces premières années, elle manifeste un net intérêt qui progresse encore dans la décennie1871-1880 où il atteint son maximum avec un rap- 
port - articles/numéros publiés, de 0,23 ; mais le déclin ne tarde pas : d'abord modeste, il s'accélère au-delà de 1890. À partir de 1911, le continent a pratiquement disparu du champ de vision. Étant donné leur chronologie, les sautes d'humeur du bulletin diocésain obéissent manifestement à d'autres préoccupations que celles qui animent le reste de la presse locale.

Un des éléments essentiels susceptible de les expliquer tient à la variation du nombre des missionnaires manceaux présents dans cette vaste zone $^{7}$, comme le suggère le rapprochement de leurs effectifs avec les fluctuations du nombre des articles publiés. C'est au moment où leur présence atteint son maximum, entre 1871 et 1880 , avec 25 missionnaires à la fois, que l'hebdomadaire accorde effectivement le plus d'attention au continent; à l'inverse, son effacement presque total, en 1911-1914, coïncide avec la faiblesse de leur présence : deux seulement. Mais la décennie phare, 1871-1880, bénéficie également d'autres circonstances propices. L'abbé Oury, aumônier de Marine, ancien membre du clergé sarthois ${ }^{8}$, qui effectue alors un long périple asiatique, communique à La Semaine du Fidèle ses observations de voyage; elles y sont longuement reproduites. Vers la fin de cette décennie, le journal de l'Évêché apporte un soutien très actif à une grande souscription lancée par la presse nationale bien pensante ${ }^{9}$ afin de venir en aide aux populations asiatiques atteintes par une terrible famine. C'est l'occasion, soit de dresser un sombre tableau des réalités du terrain, soit de présenter l'état d'avancement de l'effort financier et d'en stimuler la poursuite.

Au-delà de 1880, l'information missionnaire, essentiellement partagée jusque là entre l'Asie et le Grand Nord Canadien, où sont présents également dans les rangs des oblats de Marie Immaculée, nombre de prêtres originaires du diocèse, s'ouvre aux sollicitations de ceux qui participent à l'évangélisation plus récente des populations d'Afrique noire et d'Océanie. Cet élargissement contribue ainsi au recul des informations en provenance d'Asie. Il faut enfin tenir compte de l'impact de la législation française qui, des écoles aux congrégations religieuses, puis à la séparation des Églises et de l'État, impose de nouveaux efforts financiers aux catholiques et les détourne des préoccupations lointaines ${ }^{10}$.

Les préoccupations asiatiques de La Semaine du Fidèle s'inscrivent donc dans le cadre de l'effort missionnaire de l'Église universelle. Elles sont toutefois secondées par l'importance variable de la présence effective des missionnaires sarthois à travers le continent. La conjoncture politico-reli-

7. Outre ceux qui sont d'origine sarthoise, La Semaine ouvre aussi ses pages à des missionnaires mayennais, voire à certaines " connaissances " des dignitaires diocésains.

8. Il achèvera sa carrière comme archevêque d'Alger entre 1898 et 1909.

9. La Semaine du Fidèle du 2 février 1878 cite L'Univers et Le Monde.

10. Dans une lettre publiée par La Semaine du Fidèle (le 11 avril 1885), le RP Gouret en poste dans la région de Jaffna demande qu'on pense à lui " quand les frais d'école libre " seront épongés. Le 17 novembre 1906, l'hebdomadaire publie un appel en faveur de la Sainte Enfance dont les difficultés de l'heure en France mettent l'avenir en péril. 
gieuse nationale difficile, à la charnière des deux siècles, contribue, comme on vient de le dire, à détourner les regards du continent asiatique au profit des besoins locaux.

\section{Un intérêt sélectif}

L'ensemble des sondages réalisés dans la presse locale tout comme l'analyse du contenu de La Semaine du Fidèle, mettent aussi en évidence une gradation dans l'intérêt manifesté aux divers pays que le tableau suivant récapitule :

\begin{tabular}{|l|c|c|c|c|c|c|c|}
\hline Pays concernés & Chine & Japon & $\begin{array}{c}\text { Conflits } \\
\text { Chine/ } \\
\text { Japon }\end{array}$ & Inde & Indochine & $\begin{array}{c}\text { Autres } \\
\text { pays }\end{array}$ & Ensemble \\
\hline $\begin{array}{l}\text { Ensemble des titres } \\
\text { sauf La Semaine du Fidèle }\end{array}$ & 418 & 84 & 129 & 59 & 190 & 32 & 912 \\
$\begin{array}{l}\text { Nombre d'articles } \\
\text { \% des articles }\end{array}$ & 46 & 9 & 14 & 6,5 & 21 & 3,5 & 100 \\
\hline $\begin{array}{l}\text { La Semaine du Fidèle } \\
\text { Nombre d'articles }\end{array}$ & 113 & 29 & & 70 & 94 & 42 & 348 \\
\% des articles & 32,5 & 8,5 & & 20 & 27 & 12 & 100 \\
\hline
\end{tabular}

Avec 46 \% des articles, la Chine, presque constamment mêlée à l'actualité internationale, occupe logiquement la première place dans la presse locale; l'Indochine vient en second, tant à cause de l'incidence de sa prise de contrôle par la France dans notre vie politique nationale, que par l'attention accordée dans le sondage lui-même à la période clé que constituent pour elle les années 1880 . Le Japon, avec $9 \%$ seulement des mentions, reste très en retrait. Toutefois, son évocation, à la faveur des conflits qui l'opposent à la Chine puis à la Russie, lui confère en réalité, dans l'esprit des lecteurs sarthois, une importance nettement plus considérable qu'il n'y paraît d'abord. L'Inde, avec 6,5 \% d'articles reste largement hors du champ des préoccupations habituelles. Le reste du continent, à l'exception de la Corée, semble pratiquement ignoré.

De même qu'elle obéissait à un rythme chronologique spécifique, lié à des préoccupations particulières, La Semaine du Fidèle met aussi en œuvre une hiérarchisation originale des pays asiatiques. Si elle accorde bien à la Chine la première place, avec 32,5\% des articles (contre $46 \%$ pour l'ensemble des autres journaux), l'avance de ce pays paraît modeste puisque l'Indochine bénéficie de $27 \%$ des mentions et que l'Inde, avec $20 \%$, obtient une troisième place inattendue. Le Japon, qui ne bénéficie pas ici du surplus d'informations lié à la conjoncture internationale, reste cantonné à ses 8,5\%. La place accordée à d'autres pays ou à la région considérée dans son ensemble, s'élève à $12 \%$, suggérant une approche moins réductrice que celle du reste de la presse. La localisation des missionnaires manceaux apparaît comme l'élément explicatif essentiel de cette répartition originale des articles. En effet, sur leur effectif total de 43, Chine, Inde et Indochine 
(la première avec $28 \%$ de l'effectif, les deux autres avec $30 \%$ chacune) font à peu près jeu égal; en regard, le Japon n'accueille que quatre missionnaires (moins de $9.5 \%$ de l'ensemble). La place accordée au cas exceptionnel de $\mathrm{M}^{\mathrm{gr}}$ Berneux, martyrisé en Corée en 1866, contribue à orienter l'attention vers ce pays ${ }^{11}$.

La Semaine du Fidèle consacre également certains articles à une évocation globale de l'effort d'évangélisation mené à travers le continent; elle donne alors sa préférence à l'action de la société des missions étrangères de Paris à laquelle se sont agrégés de manière préférentielle les prêtres sarthois désireux de se consacrer à la conversion des païens ; ce qui contribue à renforcer, statistiquement, la part réservée aux " autres pays " d'Asie. Ainsi se trouve confirmée la spécificité de l'information diffusée par l'hebdomadaire de l'Évêché concernant le continent. Alors que l'ensemble de la presse locale propose une vision plutôt politique et nationale, La Semaine du Fidèle met l'accent sur la dimension locale qui s'intéresse à la vie des missionnaires sarthois et sur la dimension catholique, universelle.

\section{Le continent des tragédies}

\section{Des pays de cocagne?}

Dès 1858, L'Union évoque la Chine, ce " pays riche au-delà de toute expression ${ }^{12}$ ". Deux ans plus tard, le pillage du Palais d'Été, à Pékin, par le corps expéditionnaire franco-britannique donne de la consistance à cette appréciation ${ }^{13}$ encore en honneur au début du xx ${ }^{\mathrm{e}}$ siècle. "La Chine est riche, fertile ", écrit ainsi La Croix du Maine en 1906; " bien mise en valeur, elle pourra nourrir 800 millions d'habitants ${ }^{14}$ ".

Ce sont les trésors de l'Inde qui retiennent l'attention de L'Avenir lors de l'exposition parisienne de 1878 : "Armes précieuses, selles et hondras caparaçonnés d'or, diamants, saphirs, vaisselle et joyaux d'or et d'argent avec toutes sortes de pierreries [...] tapis et châles "; avant de s'extasier sur l'infinie diversité des productions agricoles de l'Empire, jusqu'à l'opium même ${ }^{15}$.

Une partie de la presse locale s'exalte aussi, notamment entre 1883 et 1889 , sur " les richesses immenses " et la fertilité de l'Indochine, le char-

11. La Corée bénéficie à elle seule de 17 mentions (les autres territoires évoqués sont l'Afghanistan, Bornéo, les Philippines et le Siam). Né à Château-du-Loir dans une famille d'artisans à peine pratiquants, Siméon Berneux, après des études ecclésiastiques dans le diocèse du Mans, est ordonné prêtre en 1837. Deux ans plus tard, il entre aux Missions Étrangères de Paris. D'abord envoyé au Tonkin et en Mandchourie, il devient vicaire apostolique de Corée en 1854. Arrêté, il est supplicié et meurt le 8 mars 1866. Il a été canonisé en 1984. FouQuet, Jean, Les plus belles pages des Lettres de Saint Siméon Berneux, Le Mans, Imprimerie Couilleaux, 1984.

12. L'Union, 23 septembre 1858.

13. À cette occasion, La Chronique de l'Ouest du $1^{\text {er }}$ février 1861 écrit que «chaque soldat marchait sur sa fortune, sans pouvoir la ramasser".

14. La Croix du Maine, 11 novembre 1906.

15. L'Avenir, 21 juin 1878. 
bon et les métaux précieux que recèle le sous-sol du Tonkin, cette province présentée comme la voie d'accès idéale vers la Chine du Sud et ses deux cents millions de clients potentiels pour les produits français ${ }^{16}$. Seul le Japon qui est parvenu à se mettre hors de portée des appétits extérieurs, manque à ce tableau d'honneur ambigu.

\section{Des terres de mort}

Paradoxalement, ces terres asiatiques apparaissent aussi comme autant de terres de catastrophes et de mort. Outre les tremblements de terre, redoutables ${ }^{17}$, ce sont les cyclones et tempêtes qui produisent les plus grands ravages ${ }^{18}$. C'est dans leur prolongement qu'apparaissent débordements fluviaux et inondations ${ }^{19}$; chaleur excessive et sécheresse ${ }^{20}$ ne sont pas moins à craindre pour les cultures que pour les organismes humains. Dans cet environnement hostile se développent des maladies caractéristiques : dysenterie, paludisme, fièvres de toutes sortes, auxquels se trouvent particulièrement exposés les européens. À travers toute l'Indochine comme en Inde, les soldats leur paient un lourd tribut ${ }^{21}$. Les missionnaires ne sont pas épargnés. Ainsi, ceux qui ont été envoyés en Cochinchine entre 1860 et 1875 n'y ont survécu que six ans et demi, en moyenne ${ }^{22}$. Aussi ne peut-on s'étonner que les " rescapés " des séjours extrêmes orientaux ne manifestent, quelquefois, une sorte de " tare coloniale » qui appelle l'indulgence. Ainsi pense le Procureur Général du Mans, en 1905, face à l'an-

16. L'Avenir, 15 août 1883.

17. Signalés par exemple au Su Tchuen Occidental par La Semaine du Fidèle le 27 février 1869; au Japon en octobre 1894 par L'Avenir de la Sarthe.

18. S'appuyant sur le témoignage des missionnaires, La Semaine du Fidèle évoque successivement ces cataclysmes au Bengale (24 septembre 1864), à Dacca (25 janvier 1868), à Hué (4 septembre 1869), au Bengale Oriental (3 mars 1877), dans la région de Nagasaki (10 janvier 1885 et 7 avril 1894); Le Petit Manceau évoque le cas de Hong Kong (20 septembre 1906), La Sarthe, le cyclone de Cochinchine (3 juin 1904). L'Avenir signale brièvement le 18 octobre 1877 qu'un cyclone, sur le Golfe du Bengale, l'année précédente, s'est accompagné de vagues de 15 à 20 pieds, provoquant la mort de 165000 personnes. Il ne semble pas que l'évènement ait suscité beaucoup d'émotions en Europe, à l'époque!

19. À Hué (La Semaine du Fidèle, 4 septembre 1869), en Chine (L'Avenir, 5 décembre 1883 ) puis le long du fleuve jaune (L'Avenir du 29 juillet 1889) et du Yang Tsé (L'Avenir, 22 novembre 1889); dans la région de Tokyo, avec 30000 maisons submergées en 1910 (Petit Manceau du 13 août)

20. La Semaine du Fidèle les évoque pour l'Inde (13 décembre 1862), pour l'Indochine (23 septembre 1871).

21. L'Union le signale pour l'Inde (les 27 avril et 10 juillet 1858) puis pour les troupes occupant Canton (30 octobre 1858); La Chronique de l'Ouest, en Cochinchine (24 octobre 1859) puis au Tonkin (19 mars 1884). L'Avenir de la Sarthe présente d'ailleurs cette dernière région ( 8 février 1895) comme ayant été longtemps considérée comme un "pays de mort pour les soldats français".

22. La Semaine du Fidèle, 18 décembre 1875. Louis Coutelle arrive en Cochinchine en 1873; il y meurt dès 1875 , à l'âge de 33 ans; Jean David parti en 1852, décède en Mandchourie en 1856 (à 28 ans); Louis Derenne meurt à Singapour après moins de 5 ans dans les missions, à 29 ans, etc. (Informations de La Semaine du Fidèle). 
cien directeur des "Glacières d'Indochine ", Fourmy, assassin de son épouse et de sa belle-mère, dont le réquisitoire " compréhensif " suscite tout de même la réprobation d'une partie de la presse mancelle ${ }^{23}$.

Pour les indigènes, l'irrégularité des pluies, conjuguée aux carences des administrations locales, débouche fréquemment sur de terribles famines. La presse sarthoise les évoque à travers des indications statistiques terrifiantes qui ne sont que des chiffres froids pour ses lecteurs. Ainsi, L'Avenir emprunte-t-il au Daily News, une correspondance de Pékin faisant état d'une famine qui menace de rayer de la terre 5 millions d'habitants du Chansi et y suscite des actes d'anthropologie ${ }^{24}$.

La famine qui frappe l'Inde en 1900 retient l'attention de La Sarthe comme du Petit Manceau. Cinquante millions d'hommes sont, cette fois, concernés et un dixième d'entre eux sont déjà condamnés. L'impuissance de l'administration coloniale britannique, face à l'ampleur de cette catastrophe, fournit surtout une bonne occasion de fustiger l'impéritie et le manque de cœur bien connu, de nos rivaux en impérialisme ${ }^{25}$. Le concret, on le trouve surtout dans La Semaine du Fidèle qui, par l'intermédiaire des missionnaires manceaux, dresse la chronologie serrée d'un phénomène récurrent : 1865, 1867, 1871, 1876 à 79, 1896, 1900-1901 leur fournissant en effet autant d'occasions d'appels au secours. L'un d'eux décrit la situation dans certaines provinces de l'Inde, en 1897 : "Le long des routes gisent moribonds et cadavres, proies des chiens et des chacals; des familles entières, formant des groupes de squelettes vivants, attendent la mort dans les dernières angoisses de la faim ${ }^{26}$."

Dix ans plus tard, toujours en Inde, le Père Fourcade avoue son impuissance : "Quel tourment que celui-là. J'aimerais mieux me trouver entre les mains des bourreaux de la Chine! Et si, le cœur percé, je m'enferme dans ma chambre, je n'entends tout autour que des explosions de pleurs et de sanglots. Si je sors et parcours cette foule de mères, elles se jettent à mes pieds, me présentent leurs enfants affamés ${ }^{27} \ldots$ " En 1878, dans plusieurs provinces chinoises, Monseigneur Monagatta, évoque l'extension de l'anthropophagie. Après s'être nourri de cadavres, on s'en prend aux vivants : le mari mange sa femme, les parents, leurs fils et leurs filles, les enfants, leurs parents ${ }^{28}$. Même horreur en 1900 : “Dans certaines régions de l'Inde, les deux tiers de la population ont disparu, écrit un missionnaire, les trois quarts du bétail, si ce n'est 90 sur $100^{29} \ldots$. "; « En ce moment, dit un autre, la misère est si horrible que souvent de pauvres mères nous donnent leurs enfants pour une somme dérisoire : pour 50 centimes ou 1 franc, on peut

23. Le Petit Manceau, 2 septembre 1905.

24. L'Avenir, 28 juin 1878.

25. La Sarthe, 10 avril et 21 juin 1900; Petit Manceau, 14 juin 1900.

26. La Semaine du Fidèle, 18 mai 1867.

27. La Semaine du Fidèle, 6 octobre 1877.

28. La Semaine du Fidèle du 17 août 1878, qui reprend ici une lettre adressée au Procureur des Lazaristes.

29. La Semaine du Fidèle, 30 novembre 1900. 
en obtenir ${ }^{30}$. " Et tous, de faire appel à la générosité des lecteurs pour tenter de sauver, surtout les enfants, ou tout au moins de les baptiser avant qu'ils ne meurent.

\section{Des sociétés impitoyables}

À la violence de la nature répond celle des hommes. Impossible d'échapper aux scènes de décapitation publique ${ }^{31}$, à la description des supplices infligés par la justice chinoise ${ }^{32}$, aux suicides rituels japonais ${ }^{33}$. Les révoltes qui s'allument à travers le continent, des Taiping et des Boxers chinois, aux cipayes de l'Inde sans oublier les pavillons noirs du Tonkin, véhiculent également leurs cortèges d'horreurs ${ }^{34}$.

Un peu partout aussi à travers le continent, les femmes souffrent de violences qui leur sont infligées au nom des traditions que, presque seuls, dénoncent et combattent les missionnaires. Ainsi, des chinoises, premières victimes de l'infanticide ${ }^{35}$, dont nombre de journalistes "progressistes " contestent pourtant l'ampleur sinon la réalité ${ }^{36}$. Ces femmes sont traitées comme des servantes dans leur propre maison; en surnombre, il arrive qu'on les vende à des établissements de débauche ${ }^{37}$. Beaucoup subissent les mutilations esthétiques si célèbres de leurs pieds, qui les muent en infirmes, pour la vie ${ }^{38}$. Les femmes hindoues soumises à la pression sociale connaissent d'autres malheurs comme le devoir imposé aux veuves de s'immoler sur le bûcher funéraire de l'époux ${ }^{39}$ ou, quand elles sont musulmanes, de rester " claquemurées chez elles durant toute leur vie ${ }^{40}$ "; un triste sort partagé avec les Coréennes, " pour la plupart séquestrées à leur domicile $^{41}$ ». Quoique moins dramatique, trouve-t-on acceptable l'ignorance

30. La Semaine du Fidèle, 30 mars 1900.

31. La Sarthe du 26 avril 1904 évoque ces nombreux spectateurs qui se pressent longtemps à l'avance pour assister, à Pékin, à une exécution capitale que la maladresse du bourreau rend encore plus captivante.

32. La Sarthe (27 juin 1900) qui donne de nombreux détails.

33. La Chronique de l'Ouest, 17 avril et 11 mai 1868.

34. L'Union du 20 avril 1858 évoque la répression conduite par le Mandarin Yeb à Canton, contre les Taiping : il en a fait exécuter 60000 dont certains sciés entre deux planches; dans le nord de l'Inde, les hommes des régiments cipayes, révoltés "se sont emparés par ruse des anglais qu'ils ont ensuite noyés, égorgés, brûlés ou coupés en morceaux : leurs plus brutales passions se sont données une libre carrière; ils ont exercé les cruautés les plus atroces même sur les femmes et les enfants ". (La Chronique de l'Ouest qui cite une lettre du RP Vérité, envoyée de Chittagong le 14 septembre 1857). On peut multiplier les exemples et les européens sur place ne sont pas en reste! Ce sont bien sûr les anglais qui sont montrés du doigt en matière de répression.

35. La Chronique de l'Ouest du 9 septembre 1867; Semaine du Fidèle du 30 août 1879.

36. L'Avenir de la Sarthe évoque par exemple les 26-27 février 1877 ces « fantastiques petits chinois qui sont, paraît-il, dévorés par des cochons violets ou jetés dans le fleuve jaune ".

37. La Semaine du Fidèle, 13 septembre 1879.

38. Chronique de l'Ouest, 8 mars 1867. Semaine du Fidèle, 24 août 1878.

39. Semaine du Fidèle, 11 février 1865 et 2 mai 1871.

40. Semaine du Fidèle, 20 mai 1865 et 2 mai 1871.

41. L'Avenir de la Sarthe, 28 août 1894. 
dans laquelle sont maintenues les femmes annamites, quand « sur dix mille, il n'y en a pas deux qui sachent lire ${ }^{42} "$ ?

Ces réalités illustrent la barbarie dans laquelle croupissent les peuples d'Asie. Elles contribuent à la justification morale des interventions européennes d'autant que les gouvernements locaux, incapables et sournois, ne méritent aucune considération.

\section{Des gouvernements rétrogrades et retors}

L'empereur d'Annam est " une espèce de tyran abhorré par le peuple et qui règne au milieu de la plus complète anarchie ${ }^{43}$ "; est également dénoncée la mauvaise foi des membres de la Cour de Hué qui, " comme tous les orientaux, ne respectent que la force ${ }^{44}$ ".

Le gouvernement coréen avec lequel les Français ont peu affaire, sauf en 1866 où le contre-amiral Roze, à titre de représailles, à la suite de la persécution sanglante contre les chrétiens (et de la mort de $\mathrm{M}^{\text {gr }}$ Berneux), s'empare de la capitale ${ }^{45}$, est plutôt mis en scène sur un mode ridicule. L'Avenir de la Sarthe affirme ainsi que " la Corée est une presqu'île tout à fait dans le mouvement ". La preuve? L'existence d'une loterie royale et d'un " journal officiel " dont l'utilité réside avant tout dans la publication des résultats de cette dernière ${ }^{46}$. Quant au souverain, il exerce "librement " le pouvoir, selon la Sarthe, en se " soumettant à la volonté de ses femmes ", ce qui n'est pas une mince affaire, car il dispose d'un harem bien fourni ${ }^{47}$.

Si l'on peut aussi tourner en dérision la cour de Pékin et son étiquette désuète $^{48}$, des travers autrement dangereux caractérisent le gouvernement chinois, d'autant plus redoutable que le pays, malgré ses faiblesses, est devenu un partenaire incontournable. On souligne d'abord son incapacité chronique à maintenir l'ordre dans l'immense Empire, source de dangers continuels pour les résidents occidentaux ${ }^{49}$. Mais, c'est surtout sa duplicité qui est dénoncée tout au long de la période. Dès 1844, en effet, et le

42. La Semaine du Fidèle, 26 octobre 1867. Selon le témoignage de $\mathrm{M}^{\text {gr }}$ Sohier, né dans la Mayenne en 1843, il est entré aux Missions Étrangères de Paris; envoyé en Cochinchine en 1843; Évêque en 1851, il sert d'intermédiaire en 1873 entre l'Empereur d'Annam TuDuc et Francis Garnier.

43. L'Union, 27 novembre 1858.

44. L'Avenir, 26 août 1883.

45. Le contre-amiral incendie le palais et plusieurs établissements publics; il s'empare de livres et de manuscrits " qui peuvent avoir quelque intérêt pour la science ", sans oublier des caisses de lingots d'argent d'une valeur de $197000 \mathrm{~F}$ (La Chronique de l'Ouest du 11 janvier 1867).

46. Numéro du $1^{\text {er }}$ août 1894.

47. 14 mars 1904 .

48. La Chronique de l'Ouest du 29 juin 1868; mais surtout La Sarthe qui explique notamment la procédure suivie lorsque l'Empereur désire recevoir l'une de ses deux cents femmes (6 février 1900).

49. Le Petit Manceau estime que depuis la révolte des Taiping, la Chine a connu une quarantaine de soulèvements (9 juin 1900). 
premier traité entre la France et la Chine, Le Courrier de la Sarthe évoque la perfidie du partenaire ${ }^{50}$. L'Union renchérit en 1858 : «Vanité, duplicité, hauteur qui se sert de la bassesse pour arriver à ses fins, tel paraît être l'art du Gouvernement chez ces gens-là ${ }^{11}$. " Lors de l'expédition franco-britannique de 1860, La Chronique de l'Ouest dit redouter moins les troupes que " la mauvaise foi chinoise ${ }^{52}$ ". Aussi ne faut-il pas s'étonner si, en 1900 encore, l'empereur Y Ching se fait " un devoir de violer toutes les conventions conclues avec les Européens ", conformément à la tradition nationale, à l'occasion de la guerre des Boxers ${ }^{53}$. D'ailleurs, écrit La Sarthe, " avec les chinois, la cause de la guerre est toujours un guet-apens ${ }^{54}$ ".

L'image de la richesse fabuleuse de l'Asie qui justifie l'effort de conquête entre en conflit avec une série de réalités désastreuses nées de la violence de la nature, tandis que se déploient famines et épidémies dignes de notre Moyen Âge. Les sociétés asiatiques vivent donc en permanence dans le drame aggravé par le cycle des révoltes et des répressions impitoyables conduites par des gouvernements d'autant plus dangereux qu'ils sont incohérents. Le triste sort réservé aux femmes apparaît comme le symbole le plus éclatant de la barbarie. Quelle chance d'être né dans la Sarthe en pays civilisé et chrétien!

\section{Le tableau d'honneur des peuples}

\section{Coréens, Indochinois, Indiens, des approches sommaires}

Les Coréens, placés bien malgré eux, sous les feux de l'actualité en 1894 à l'occasion de la guerre sino-japonaise, restent mal connus; ils font l'objet d'appréciations contradictoires. "Paresseux et déprimés mais intelligents " selon certains ${ }^{55}$, ils sont, pour Siméon Berneux qui a partagé leur vie, " d'une énergie que je n'ai rencontré nulle part ailleurs " et d'insister sur leur courage ${ }^{56}$. Leurs femmes sont " charmantes, souvent jolies "; mais faut-il croire cet autre témoin qui déclare ensuite que la séquestration à domicile est de rigueur pour elles et que, lorsque, par exception, elles sont contraintes de sortir, elles portent un voile gris ou blanc sur le visage ${ }^{57}$ ?

Les Indochinois sont, au contraire, familiers aux Sarthois, à qui on les a présentés de manière plutôt positive. Menant une vie frugale, ils se révèlent doux, d'un heureux tempérament, hospitaliers ${ }^{58}$. Les jugements sont

50. Les chinois ont déjà montré leur " compétence " en modifiant unilatéralement le texte du Traité de Nankin conclu avec le Royaume Uni en 1842.

51. 9 mars 1858 .

52. 14 novembre 1960 .

53. La Sarthe, 26 juin 1900.

54. La Sarthe, 7 août 1900.

55. L'Avenir de la Sarthe, 28 août 1894, qui emprunte sa présentation à " une revue anglaise ".

56. L'Union, 6 juillet 1858.

57. L'Avenir, 28 août 1894.

58. La Semaine du Fidèle, 30 juillet 1865; 10 septembre 1870. 
plus partagés pour ce qui touche à leur ardeur au travail, mais leur habilité comme artisan d'art, est unanimement reconnue ${ }^{59}$. En matière militaire, leurs adversaires conviennent de leur courage comme de leur aptitude à remuer la terre dans le combat défensif ${ }^{60}$. Leur défaut principal paraît être le goût prononcé qu'ils manifestent pour les jeux de hasard qui se mue chez certains en une passion dévorante et destructive. Ils ne sont pas non plus à l'abri des tentations de l'opium ${ }^{61}$. Habitués à obéir à des maîtres, les Annamites disposés à se plier au pouvoir des français, en sont parfois détournés par les exigences excessives de l'administration coloniale ${ }^{62}$; d'où la renaissance périodique des révoltes et la persistance du banditisme ${ }^{63}$, encouragées par des " lettrés " qui regrettent leur ancien pouvoir et savent mobiliser leurs compatriotes au nom des traditions menacées ${ }^{64}$.

L'image optimiste mais superficielle des Indiens s'appuie sur des constructions qui doivent beaucoup à l'imagination, telle la mise en scène réalisée dans le cadre de l'Exposition Universelle de Paris, de 1878, évoquée en ces termes par L'Avenir de la Sarthe : "Un peuple heureux de ses mœurs simples, de sa vie frugale et de sa culture empruntée aux grandes épopées religieuses qui lui fournissent la plus haute expression de sa littérature, de son art, de sa civilisation stéréotypée depuis 2000 ans ${ }^{65}$ "; moins positivement, un peuple " nonchalant, amateur de la coutume, faisant de père en fils, ce que faisaient les ancêtres ${ }^{66}$ "; ou virant au noir, sous la plume d'un missionnaire : "Qui dit indien, dit tout ce qu'il y a de plus misérable sur la terre ${ }^{67}$."

Cette dernière appréciation est évidemment étayée par le retour périodique des famines dramatiques, aggravées par le clivage des castes (et les missionnaires, qui sont les témoins les plus loquaces, ont essentiellement affaire aux parias, presque les seuls candidats à la conversion ${ }^{68}$ ). Les riches ne manifestent aucune pitié; même la famine n'empêche pas le rajah d'exiger la rente de la terre, l'usurier de faire saisir et vendre les bœufs de ses obligés insolvables, les marchands, d'accaparer le peu de grain encore disponible ${ }^{69}$.

59. La Semaine du Fidèle, 29 novembre 1879.

60. La Chronique de l'Ouest, 15 juillet 1859; 17 avril 1861; La Semaine du Fidèle, 15 janvier 1884. On pense à Dien Bien Phu!

61. La Semaine du Fidèle, 7 novembre 1874.

62. La Semaine du Fidèle, 21 mai 1892.

63. Par compte, Semaine du Fidèle, 28 août 1886; L'Avenir de la Sarthe, 6 février 1889, 26 septembre 1894, 9 janvier 1895; La Sarthe, 4 mars 1900, etc.

64. La Semaine du Fidèle, 13 juin 1874; 24 octobre 1885.

65. Série d'articles entre le 10 et le 22 juin 1878.

66. La Semaine du Fidèle, 15 décembre 1877.

67. La Semaine du Fidèle, 13 octobre 1877.

68. La Semaine du Fidèle, notamment, 18 novembre 1871, 31 décembre 1901, 7 mars 1902, 24 octobre 1908.

69. La Semaine du Fidèle, 27 décembre 1901, selon une lettre de missionnaire. 


\section{Les Chinois, du mépris à l'admiration}

Les Chinois sont généralement cloués au pilori de l'opinion. On évoque leur pullulement : 400 millions de " jaunes ", plus que toute la population de l'Empire britannique, mais " ce sont des Chinois ${ }^{70}$ ! " Autrement dit de grands enfants qu'on ne peut prendre au sérieux, de quelque côté qu'on les considère.

Il en va ainsi de leur "science " dont l'explication des éclipses de lune donne un aperçu : elle y voit en effet des tentatives du dragon céleste pour dévorer le satellite de la terre, mais des concerts de gongs, casseroles, crécelles, tambours, pétards et cris de toutes sortes le mettent en fuite ${ }^{71}$, voilà qui permet de juger du savoir du marquis Tseng, ambassadeur de Chine en France, en 1883, considéré comme " très savant, au moins essciences chinoises ${ }^{72}$ ". De la "musique chinoise ", aux invraisemblables sonorités, et qui est tout, sauf de la musique ${ }^{73}$. De la beauté chinoise dont les critères laissent pantois les Européens : « Le front et la face bien larges, le nez court, des petits yeux fendus, de grandes oreilles et un embonpoint bien marqué ${ }^{74}$. " On peut dès lors s'inquiéter de la distinction de l'épouse de notre fameux ambassadeur, considérée " comme très jolie pour une chinoise ${ }^{75}$ ".

Et puis, il y a la mode : "Avec leurs tresses sur le dos, ils ressemblent à des dames en camisole de nuit ${ }^{76}$ "; la langue chinoise, avec "ses noms désarticulés en syllabes barbares " qu'on ne peut prononcer sans rire ${ }^{77}$; l'armée chinoise, cohue inefficace qui " manifeste un acharnement incomparable à se faire battre ${ }^{78}$ " tandis que ses chefs compensent les échecs par des vantardises dignes de nos " midis $^{79} "$; le travail chinois, dans un pays où " un quart de la population est occupé à traîner les trois autres quarts sur des espèces de civières ${ }^{80}$ ".

Peuple avide d'argent qui cède volontiers pour quelques pièces de monnaie ses infortunés enfants ${ }^{81}$, le peuple chinois s'assure, par contre, une redoutable réputation en matière de business. En 1868, on s'en va répétant qu' " un Russe vaut deux Juifs et un Chinois quatre Russes ${ }^{82}$ "; mais comme on n'arrête pas le progrès, en 1888, " il faut neuf juifs pour rouler un

70. L'Avenir, 10-11 juin 1878; La Sarthe, 3 juillet 1900.

71. L'Avenir, 4 juin 1878.

72. L'Avenir, 18 décembre 1883.

73. Le Courrier de la Sarthe, 21 février 1845; L'Avenir, 4 juin 1878.

74. L'Union, 30 octobre 1858.

75. L'Avenir, 18 décembre 1883.

76. Le Petit Manceau, 15-16 octobre 1911.

77. L'Avenir, 4 juin 1878.

78. La Sarthe, 25 juin 1900.

79. L'Avenir, 6 mai 1895.

80. Semaine du Fidèle, 13 décembre 1873; selon Ed. Langlais, missionnaire en Chine.

81. Circulaire de $\mathrm{M}^{\mathrm{gr}}$ Bouvier, au Clergé « pour recommander la propagation de la Foi et régler l'œuvre de la Sainte Enfance dans le diocèse " (5 avril 1851).

82. La Chronique de l'Ouest, 2 octobre 1968. 
Américain et neuf américains pour rouler un Chinois ${ }^{83}$ ". En fin de compte, on a du mal à plaindre ce " malheureux peuple attardé depuis des siècles dans son fanatisme et ses superstitions ${ }^{84}$ " pour ne rien dire de la déchéance résultant de l'usage de l'opium (encouragé, c'est vrai, par l'Angleterre) ${ }^{85}$, lorsque les calamités naturelles et les famines s'abattent sur lui.

Il existe pourtant un autre regard sur les Chinois, "peuple assez civilisé, bien au-dessus du peuple indien ${ }^{86}$ ". Certains européens qui les ont côtoyés, soulignent leurs qualités : sobriété, acharnement au travail, intelligence, aptitudes particulières pour les activités commerciales, solidarité familiale et raciale, grande faculté d'adaptation ${ }^{87}$. Un conférencier intervenant au Mans en 1885, après avoir vécu 35 ans en Chine et dont L'Union Républicaine reprend longuement les propos, esquisse une vision encore plus renversante pour les sarthois habitués au dénigrement lorsqu'il s'agit des Chinois. Après avoir rappelé les découvertes dues à la Chine et qui ont, dès longtemps, enrichi l'ensemble de l'humanité, l'orateur souligne les mérites de la philosophie et des arts chinois, le caractère raisonnable de nombreux traits de l'organisation politique et sociale du pays, avant de conclure que "sur plus d'un point, notre civilisation pourrait prendre modèle sur la Chine ${ }^{88}$ ".

Sans aller jusque là, ceux qui regardent ce peuple avec sympathie insistent sur deux aspects où il fait la démonstration de ses aptitudes : l'agriculture et les arts. Ainsi, dans une série de lettres à sa mère, partiellement reprises dans La Semaine du Fidèle, Henri Grémillon, missionnaire jésuite, originaire du Mans, souligne le travail remarquable des paysans, leur volonté de mettre en valeur tout le potentiel naturel du pays, qu'il s'agisse des pentes des montagnes comme du fond des vallées; leur ingéniosité aussi, en matière d'irrigation ${ }^{89}$. En 1900, Le Petit Manceau (" radical ") rejoint le jésuite dans son éloge du paysan chinois, " le premier agriculteur du Monde " dont le pays " est décrit avec admiration par tous les voyageurs depuis Marco Polo ${ }^{90}$ ".

En matière artistique, c'est un autre jésuite, Louis Gaillard, qui donne le ton, dans un article emprunté par l'hebdomadaire de l'évêché aux Études, revue de son ordre ${ }^{91}$ après y avoir décrit " les collections d'art chinois magnifiques ", vues à Pékin, il célèbre la Grande Pagode, " une des plus

83. La Semaine du Fidèle, 31 mars 1888, selon $\mathrm{M}^{\mathrm{gr}}$ Reynaud, évêque en Chine Occidentale.

84. La Semaine du Fidèle, 17 août 1900. Circulaire de $\mathrm{M}^{\mathrm{gr}}$ de Bonfils, " ordonnant des prières pour les victimes des massacres en Chine et le succès de nos armes".

85. La Chronique de l'Ouest, 6 juillet 1960; L'Avenir de la Sarthe, 28 juin 1878.

86. La Semaine du Fidèle, 19 septembre 1891, etc.

87. La Semaine du Fidèle, 13 décembre 1873 (selon le RP Langlais). Semaine du Fidèle, 9 et 12 mars 1872, témoignage de l'abbé Oury, alors aumônier de Marine, lors d'une croisière en Asie.

88. L'Union Républicaine, 21-23 mars 1885.

89. La Semaine du Fidèle, 2 et 23 octobre 1886; 5 et 26 novembre 1887.

90. Le Petit Manceau, 2 juillet 1900.

91. Revue fondée en 1856. 
belles choses qui existent en Asie ". Il vante encore " l'admirable " art chinois du XV ${ }^{\mathrm{e}}$ siècle pour conclure que " si les amateurs le connaissaient sous cet aspect, beaucoup changeraient d'avis. Les chinoiseries populaires, connues chez vous, dit-il, ne sont que des caricatures ${ }^{92}$ ". Quant à La Sarthe, elle emprunte à un ouvrage publié par $\mathrm{M}^{\mathrm{gr}}$ Favier, évêque de Pékin devenu un héros depuis sa résistance pendant la révolte des Boxers, un long passage où l'auteur décrit avec admiration les tombeaux édifiés par les empereurs Ming en les comparant aux chefs-d'œuvre de l'art mondial ${ }^{93}$.

Ayant commencé de manifester de la sympathie pour les Chinois, on en vient à s'interroger sur la cause de leur xénophobie ${ }^{94}$. "La Chine ouverte, voilà le grand grief, écrit La Semaine du Fidèle, citant Stephen Pichon, ambassadeur de France à Pékin (et anticlérical notoire), 500 millions d'hommes apathiques et sans nerfs et jusqu'alors figés dans la contemplation des vieilles coutumes, voyaient tout à coup leurs frontières violées, leur civilisation bousculée, leurs manies dérangées, leur commerce dépassé ${ }^{95}$. " Il y a là comme une invitation à prendre en considération le point de vue chinois pour essayer de le comprendre. C'est un changement considérable d'attitude.

\section{Les extraordinaires petits Japonais}

La presse sarthoise a d'abord manifesté quelque difficulté à saisir la portée des troubles sanglants qui affectent le Japon, lors de l'ouverture de l'ère Meïji ${ }^{96}$. Aussi a-t-elle accueilli avec soulagement la déclaration du Mikado s'engageant à respecter les traités conclus précédemment avec les puissances étrangères et manifestant sa volonté d'ouverture ${ }^{97}$. Bientôt, elle tresse des couronnes au gouvernement et aux dirigeants japonais, un phénomène qui atteint son apogée à la faveur de la guerre sino-japonaise de 1894, mais se prolonge au-delà de la confrontation avec notre allié russe à propos du contrôle de la Mandchourie en 1904-1905.

"C'est, explique L'Avenir de la Sarthe, que depuis quelques années, le Japon est entré en plein dans la civilisation : les sciences et les arts y sont à l'honneur. On y a adopté une constitution tout à fait moderne et établi le suffrage universel. Tous ces progrès sont dus en grande partie à l'initiative de l'Empereur qui est un homme de paix et de sciences ${ }^{98}$."

92. La Semaine du Fidèle, 20 et 27 juillet 1900.

93. La Sarthe, 22 octobre 1900.

94. Xénophobie souvent évoquée sans explication. Ainsi, dans L'Union (23 septembre 1858), La Semaine du Fidèle (31 août 1878), Le Petit Manceau et La Sarthe, à de nombreuses reprises dans le cours de l'année 1900.

95. La Semaine du Fidèle, 30 août 1901.

96. La Chronique de l'Ouest du 17 avril 1868 évoque la décapitation de nombreux fonctionnaires et les suicides en cascade. Le 2 septembre 1868, elle décrit les affrontements d'une véritable guerre civile à travers l'archipel, accompagnés d'une phase de persécution anti-chrétienne.

97. Le 26 mars 1868 .

98. L'Avenir, 3 août 1894. La tolérance religieuse acquise depuis 1873 est confirmée par un décret impérial en août 1880 (La Semaine du Fidèle, 15 novembre 1884). 
Son épouse, Harn-Ko, " qui a compris la grandeur de sa mission », est associée à cet hommage :

"Elle a diminué les rigueurs de l'étiquette, s'est rapprochée de son peuple pour voir de près ses souffrances et ses besoins. Elle a fondé des écoles et des hospices. Elle s'est attachée à relever la condition de la femme ${ }^{99}$. "

Ce couple exemplaire, qui conduit le Japon à marche forcée vers le progrès, en suivant le modèle de la civilisation occidentale, a su s'entourer de collaborateurs tout aussi remarquables. Le maréchal, comte Yamagata, " qui a adhéré immédiatement à la Révolution " (de 1868) et auquel sont dues la modernisation de l'armée et la création d'une école militaire supérieure où il a fait venir pour y professer " nos plus instruits généraux ". Premier Ministre et Président du Conseil privé, il abandonne ses fonctions pour diriger l'armée lorsque commence la guerre de 1894 contre la Chine ${ }^{100}$.

Dix ans plus tard, lorsqu'éclate la confrontation avec la Russie, La Sarthe présente à ses lecteurs « un (autre) héros japonais », le général Nogi. Lui aussi a fait partie de ceux qui ont permis « le passage de l'Empire, d'une féodalité du Moyen Âge à la quintessence de la bureaucratie du Xxe siècle ». Gouverneur de Formose (en 1896-98), bientôt vainqueur des Russes à Port-Arthur, c'est un véritable personnage cornélien. Au moment de partir pour le front, en effet, apprenant que l'un de ses deux fils vient d'être tué à la bataille de Nanshan, il dit à son épouse " sans que son visage trahisse le moindre signe de sa douleur " : " Ne procédez pas encore à des cérémonies funèbres. Mes deux fils et moi avons offert notre vie pour l'empereur quand la guerre a commencé. Un seul service funèbre peut, d'ici à bientôt, être célébré pour nous trois ${ }^{101}$. " Le comte Ito, " le personnage le plus considérable de la révolution qui a transformé le Japon " et a réussi à faire de son pays " une des nations des plus civilisées ", a droit, lui aussi, aux honneurs de la presse sarthoise. La déclaration qu'il publie lors de sa prise de fonction comme résident général en Corée, après la victoire sur la Russie, dans laquelle il définit la conception de sa mission - la modernisation du pays qui lui est confié - suscite l'admiration du Petit Manceau qui en cite de larges extraits ${ }^{102}$.

À partir du moment où il est engagé par ses dirigeants dans la voie d'une modernisation à l'occidentale, le peuple japonais tout entier bénéficie d'un capital de sympathie que ses représentants savent entretenir avec habileté. En témoigne par exemple le discours du Commissaire Général du Japon à l'Exposition Universelle de Paris en 1878 où, moitié dans sa langue et moitié dans la nôtre, il remercie les Français, " nos frères [...] à qui nous devons de connaître les véritables bienfaits de la civilisation ${ }^{103}$ ", ou la participation au service funèbre célébré à la mémoire du Président Carnot, assassiné en la Cathédrale de Tokyo. Le "Palais " y prête le concours de sa

99. L'Avenir, 23 septembre 1894.

100. L'Avenir, 4 octobre 1894.

101. La Sarthe, 5 février 1905.

102. Le Petit Manceau, 23 décembre 1905.

103. La Chronique de l'Ouest, 21 juin 1878. 
musique; le ministère et les grands corps de l'état y assistent au grand complet ainsi que de nombreux généraux arborant « toutes leurs décorations françaises et russes ${ }^{104}$ ". Considéré comme " un peuple pacifique, sobre et travailleur " par le radical Petit Manceau ${ }^{105}$, le peuple japonais est aussi, aux yeux de nos missionnaires " le plus intelligent et le mieux doué de tous les peuples païens qui existent sur la terre ${ }^{106}$ ». Du reste, certains habitants de l'archipel ont donné, de longue date, des preuves éclatantes de leur aptitude à embrasser le catholicisme : Pie IX a canonisé solennellement vingt martyrs japonais du XVI ${ }^{\mathrm{e}}$ siècle en juin $1862^{107}$ et trois ans plus tard, on a découvert avec stupéfaction l'existence d'une chrétienté " cachée ", à Nagasaki, restée fidèle à sa foi, malgré plusieurs siècles d'isolement ${ }^{108}$.

L'aptitude de ce peuple à s'adapter aux exigences de la modernisation suscite l'admiration, depuis la fondation des premières bourses de commerce ${ }^{109}$ jusqu'à l'ouverture des mines de charbon et aux créations industrielles ${ }^{110}$. Il n'est pas certain cependant que tout aille pour le mieux dans le meilleur des mondes et le RP Pélu, présent sur place, montre l'exode rural et l'errance d'île en île des familles à la recherche d'une nourriture improbable ${ }^{111}$; mais, son modeste témoignage ne pèse pas lourd face au concert des louanges qui envahit la presse dès qu'on évoque le Japon. Car les réformes spectaculaires continuent d'aller bon train. L'usage de l'opium est sévèrement réprimé ${ }^{112}$, le duel est interdit ${ }^{113}$, le système carcéral est renouvelé ${ }^{114}$, surtout, l'émancipation des femmes avance à grands pas; elle touche spectaculairement celles qui appartiennent à la bonne société et se voient désormais autorisées à accompagner leurs époux dans les réunions et les réceptions jusque là exclusivement réservées aux hommes. Le rôle des geishas qui fait rêver les journalistes sinon les Sarthois, s'en trouve modifié mais nullement aboli ${ }^{115}$. Lors de la guerre sino-japonaise de 1894, on voit même des femmes se porter volontaires pour partir sur le front comme infirmières, voire comme combattantes ${ }^{116}$.

104. L'Avenir de la Sarthe, 27 août 1894.

105. Le Petit Manceau, 11 septembre 1905.

106. La Semaine du Fidèle, 7 octobre 1893.

107. Une série d'articles est consacrée à l'évènement, par La Semaine du Fidèle, entre le 7 mars et le 2 mai 1893 .

108. La Semaine du Fidèle, 22 mars 1879.

109. La Chronique de l'Ouest, 30 janvier 1859.

110. Le Petit Manceau, 17 décembre 1900.

111. La Semaine du Fidèle, 19 janvier 1884 et 7 avril 1894.

112. L'Avenir, 25 mai 1878.

113. La Semaine du Fidèle, 13 décembre 1890 et 24 janvier 1891.

114. L'Avenir du 25 mai 1878 fait visiter à ses lecteurs le bagne modèle de Tsukuda-Jima, près de Tokyo; on y rencontre des prisonniers affairés à diverses productions; d'autres qui fréquentent l'école de la prison. Les conditions d'hygiène et de " confort " sont telles que la mortalité y est inférieure de moitié à celle que l'on enregistre en Europe dans les établissements de même type.

115. La Sarthe du 7 avril 1904 présente longuement cette « institution " ainsi que les transformations qu'elle connaît alors.

116. L'Avenir, 19 septembre 1894. 
C'est pourquoi, " ce petit peuple d'étagère, ces bibelots vivants qu'on croyait bons seulement à ciseler des ivoires exquis et à dessiner des fleurs de rêve avec dans le fond, la crête du Fusi Yama ${ }^{117}$ " surprend tout le monde en remportant une victoire apparemment facile sur la Chine en 1894 dont les grandes puissances s'emploient à limiter aussitôt la portée pratique ${ }^{118}$. Cette victoire est un peu la notre car cette armée a pris ses leçons auprès de cadres de l'armée française enseignant à Tokyo ${ }^{119}$ tandis que des officiers japonais ont régulièrement effectué des stages chez nous ${ }^{120}$.

Dix ans plus tard, bien que nos alliés russes fassent, cette fois, les frais de la nouvelle démonstration, nos généraux s'émerveillent devant le comportement de ces officiers nippons, " admirables d'entrain et d'intrépidité " qu'on a vus " gantés, la cigarette aux lèvres, donnant leurs ordres pendant que les balles ennemies fauchaient les hommes autour d'eux ", tandis que leurs " vaillants petits soldats marchent à la mort " sans hésiter, sans broncher, dédaignant de profiter des couverts, presque froidement, en formations régulières, d'un pas résolu, à peine accéléré, cadencé par une sorte de cri rauque, sans grande force, sans chaleur excessive : admirable exemple des résultats que peut enfanter un ardent patriotisme secondé par un esprit de corps remarquable et par une rigoureuse discipline ${ }^{121}$. En songeant aux menaces qui planent sur la France, certains de nos chefs militaires envient manifestement à leurs homologues japonais un tel instrument de combat.

Mais l'inquiétude se mêle maintenant à l'admiration. Que vont faire les vainqueurs? Nos possessions indochinoises ne sont-elles pas menacées par leurs ambitions ${ }^{122}$ ? Sans oublier les conséquences désastreuses de leur victoire pour l'image des Européens aux yeux de l'ensemble des peuples asiatiques $^{123}$. Nous ne sommes pas les seuls à devoir nous inquiéter. En août 1914, Le Petit Manceau rappelle en effet une prophétie du Général Nogi qui prévoyait dès 1905 la victoire française dans un nouveau conflit franco-

117. L'Avenir de la Sarthe, 5 octobre 1894.

118. À la demande des " puissances ", le Japon renonce notamment à la péninsule de Liao Tung qu'il voulait conserver. "Acte de sagesse et de sens politique tout à son honneur " écrit L'Avenir de la Sarthe du 27 avril 1895 qui «montre que le Japon ne manque pas d'esprits souples et pénétrants et qu'il est le champion de la civilisation en Extrême-Orient ". 119. L'Avenir, 4 octobre 1894.

120. Le 6 mai 1889, L'Avenir de la Sarthe annonce le passage au Mans d'un prince japonais, Kan-In, sorti de Saint-Cyr et poursuivant sa formation dans un régiment à Tours. Il est venu dans notre ville pour rendre visite à l'un de ses anciens instructeurs. On sait aussi comment la marine de guerre nippone, à ses débuts, doit beaucoup à la France. (Touchet, Elisabeth de, Quand les Français armaient le Japon, Rennes, PUR, 2003).

121. La Sarthe du 29 février 1907 citant un ouvrage du Général Frey qui fut commandant des Forces Françaises durant la campagne de Chine. Notons aussi que dès la période de la guerre contre la Chine, les Japonais s'étaient montrés capables de contrôler les informations concernant le conflit (L'Avenir de la Sarthe, 17 septembre 1894).

122. Le Nouvelliste de La Sarthe du 5 janvier 1905 affirme par exemple que " les ambitions japonaises n'ont pas de limites " et que de ce fait, une grave menace pèse sur l'Indochine dont la défense n'a pas été préparée.

123. Les 18 janvier et 22 mars 1905, La Sarthe évoque en première page le "péril jaune ". 
allemand mais aussi le succès de son propre pays sur les États-Unis dans une guerre pour la domination du Pacifique ${ }^{124}$ !

Pour se rassurer à bon compte, on rouvre alors la boîte des vieux poncifs et l'on renvoie les japonais d'où ils viennent, dans le troupeau des peuplesenfants. Et c'est l'Amiral Tojo devant Port-Arthur " jugeant le tempérament russe d'après le sien, comme sont portés à le faire les enfants et les barbares ${ }^{125}$ ". Ou encore, cette description grotesque d'une population avide d'adhérer au monde moderne, mais inculte, présentée par la Sarthe en 1904 :

"Quand les sujets du Mikado décidèrent que l'emblème type de la civilisation devait être le chapeau haut de forme qu'arborent ici nos croquemorts et nos "corpuchics", ce fut un véritable délire. On vit dans les rues de Tokyo des gentlemen à peau jaune, aux petits yeux bridés, porter d'énormes gibus qu'ils protégeaient de la pluie avec des ombrelles en papier brûlé... Des paquebots arrivèrent, bondés de toutes les vieilles nippes, de toutes les vieilles horreurs que les marchandes à la toilette de Paris et de Londres n'avaient plus l'espoir de vendre, et tout cela fut acheté par les Japonais à des prix insensés, fabuleux. Pendant quelque temps, on aurait pu croire qu'une immense mascarade avait lieu. Jamais le Mardi Gras en Europe ne vit des scènes aussi comiques ${ }^{126}$."

Au total, une vision caricaturale et souvent méprisante de ces peuples que l'attachement à des traditions surannées condamne au déclin et à la sujétion; l'esquisse aussi d'une hiérarchisation fondée avant tout sur l'aptitude à adopter le point de vue européen sur le monde, et ses techniques. Le regard porté sur les chinois évolue cependant mais la vision positive provient surtout des missionnaires, elle ne concerne par conséquent qu'une partie limitée de l'opinion locale. Le Japon bénéficie, quant à lui, d'une image très remarquable dans la mesure où il semble se mettre sans réserve à l'École de l'Occident et se comporter notamment en disciple de la France. Mais cet élève qui réussit trop bien, suscite la crainte au début du $\mathrm{XX}^{\mathrm{e}}$ siècle; on cherche à s'en défendre en retournant au mépris jusque là refoulé, mais rempart désormais insuffisant pour assurer le maintien de la suprématie européenne sur Asie.

\section{L'Inde et l'Extrême-Orient dans la vie quotidienne des Sarthois}

\section{Une percée modeste dans le décor quotidien et la fête}

À s'en tenir aux informations de la presse locale, l'Inde et l'ExtrêmeOrient occupent une place quasi nulle dans la vie économique sarthoise. Tout au plus relève-t-on quelques indications de caractère anecdotique telle que la fourniture de vitraux à des églises chinoises et japonaises, par la manufacture des Carmélites du Mans ${ }^{127}$ ou la fabrication en 1879 d'un

124. Le Petit Manceau, 13 août 1914.

125. La Sarthe, 23 février 1904.

126. La Sarthe, 17 février 1904.

127. La Semaine du Fidèle, 31 août 1897 et 19 juillet 1873. L'un de ces vitraux est destiné à une église de Nagasaki. 
carillon de six cloches destiné à la Cathédrale de Saigon, par la fonderie Bollée ${ }^{128}$ dont le nom est plus communément associé à l'histoire de l'automobile. De même, ni la publication d'une note d'E. Guéranger, dans le bulletin de La société d'Agriculture de la Sarthe, concernant la culture de l'igname de Chine, au Mans ${ }^{129}$, ni l'admiration manifestée par le jury du Comice Agricole de Mamers devant le verrat anglo-chinois, présenté par M. L'Aigle de Mazures ${ }^{130}$ n'entraîneront de bouleversement dans l'agriculture locale.

En matière de vie quotidienne, l'Extrême-Orient commence en fait à investir directement les intérieurs, sous forme de petits tableaux, gravures et images ${ }^{131}$, d'objets symboliques de l'étrangeté de la vie asiatique ${ }^{132}$ de figurines chinoises ${ }^{133}$ ou encore de vaisselle fine ${ }^{134}$. La mode de ces objets s'est développée depuis la Monarchie de Juillet et ses initiatives en direction de la Chine ${ }^{135}$. Elle s'est trouvée renforcée après le pillage du palais d'été de Pékin par le corps expéditionnaire franco-britannique. À cette occasion, le Général Cousin-Montauban a fait parvenir à l'Empereur Napoléon III des " objets ayant de la valeur au point de vue artistique ou par leur antiquité, [...] des curiosités assez rares en France ${ }^{136}$ ". Elle reçoit sa consécration avec l'inauguration du Musée Guimet à Paris, le 20 novembre 1889, en présence des plus hautes autorités de l'État qui en

128. La Semaine du Fidèle, 10 mai 1879.

129. Bulletin $\mathrm{n}^{\circ} \mathrm{XI}$, années 1854-1855, p. 164-168.

130. L'Union, 2 décembre 1858.

131. On trouve, par exemple, un petit tableau chinois, estimé 8 francs, dont la succession de l'abbé Davost, curé de la Trinité de Laval, en 1876. (Arch. dép. de la Mayenne, 155Q55 Laval). Le RP Anastase Busson envoie en 1905 plusieurs centaines de cartes " donnant des vues de l'Inde très bien faites " à son ami, le Doyen de la Fresnaye, pour être distribuées à tous ceux qui feront des offrandes en faveur de sa mission. (La Semaine du Fidèle, 20 mai 1905).

132. L'abbé Furet, missionnaire au Japon entre 1855 et 1869, fait parvenir à ses amis manceaux des cadeaux typiques (communication de Patrick Beillevaire, chargé de Recherche au CNRS, dans le cadre du séminaire de B. Waché, en 1999, à l'Université du Maine). Jules Bedeau, un charron, originaire d'Averton (Mayenne), militaire au $26^{\mathrm{e}}$ régiment d'artillerie du Mans, qui s'est porté volontaire pour l'expédition de Chine (avec 30 autres de ses camarades) revient avec quelques cadeaux à offrir à ses proches et à ses amis. Voir l'Oribus n 32, décembre 1992 : "Un Mayennais en Chine ". Un de ses descendants, François Pavé, prépare actuellement un travail sur le récit de ce "voyage " à l'Université du Maine.

133. Des articles de L'Union Républicaine (29 mars 1885) et de La Semaine du Fidèle (27 juillet 1900) montrent que les " chinoiseries " sont familières aux lecteurs.

134. Dans le cadre de la cavalcade organisée au Mans en 1911, un char présente les arts japonais où " la porcelaine, surtout, est admirablement représentée ". (Le Petit Manceau du 28 septembre 1911). M. Leroux, bijoutier réputé du Mans reçoit en cadeau de mariage, en 1910, un service de vaisselle " chinois " qui se révèle finalement être une production de Haviland, à Limoges. (Témoignage de sa fille, en 2004).

135. C'est entre 1839 et 1845 que le mot " chinoiserie " commence à être employé pour désigner un bibelot de ce pays.

136. La Chronique de l'Ouest du 26 décembre 1860 cite longuement la lettre du Comte de Palikao à l'empereur. C'est avec ces objets que l'impératrice Eugénie fait organiser un "musée chinois " au palais de Fontainebleau. 
parcourent successivement « la salle indienne des trois salles chinoises et la galerie japonaise, si curieuse avec ses mille objets ${ }^{137}$ ".

L'Asie du Sud et de l'Est pénètre également dans les jardins. La société d'horticulture de la Sarthe commence en effet à développer un jardin d'expérimentation et d'acclimatation au Mans, à partir de 1855, sur les plans d'Adolphe Alphand, le fameux organisateur des espaces verts du Paris haussmannien. Fidèle à ses choix, il encourage l'implantation d'essences asiatiques dès 1859. Au début du Xx $\mathrm{Xx}^{\mathrm{e}}$ siècle, on dénombre ainsi au " Jardin des Plantes " du Mans une centaine d'arbres différents venus de l'Himalaya comme de la Chine, de l'Inde ou du Japon, ainsi qu'une quarantaine de types d'arbustes d'ornements ${ }^{138}$. Un certain nombre d'entre eux s'introduisent, par l'intermédiaire des sociétaires, dans les jardins privés.

C'est, semble-t-il, tardivement que l'Asie gagne aussi sa place dans la fête populaire Son évocation a été relevée à la faveur de quatre manifestations, trois au Mans et une à Montfort-Le-Rotrou (une commune de 900 habitants située à une vingtaine de kilomètres du chef-lieu du département) entre 1906 et 1914. Une enquête plus systématique confirmerait probablement le développement de cette référence. Au Mans, en 1906, c'est la dimension burlesque et le ridicule qui sont exploités à travers la présentation de " nains turcs et de géants chinois 139 "; de même, à Montfort en 1914 avec un mandarin en fauteuil roulant, promené par deux de ses sujets qui closent un défilé festif et provoquent l'hilarité des spectateurs ${ }^{140}$.

La ville dispose évidemment d'autres moyens et " la cavalcade orientale de bienfaisance " qu'elle organise en 1911, dans le prolongement d'une grande exposition, met en scène un éléphant, 400 figurants à pied, 100 cavaliers, 100 musiciens, tous vêtus de costumes extraordinaires et de parures dont on a été chercher les modèles au musée Guimet ${ }^{141}$. Ils accompagnent les évolutions d'une dizaine de chars dont les thèmes choisis sont au-delà de la seule volonté de distraire. Les inquiétantes divinités indoues sont évoquées par deux reconstitutions; la Chine apparaît à travers la mise en scène des chasseurs primitifs mandchous placés dans un paysage enneigé, symboles d'un passé révolu, suivi des chars du printemps et du tissage, évocations du renouveau puis du travail raffiné des artisans chinois.

Le Japon traditionnel, à lui seul, sert de support à la moitié des mises en scène, des arts aux parfums, aux maisons de thé et aux geishas, sans

137. L'Avenir de la Sarthe consacre à l'inauguration une demi-colonne en première page d'un numéro du 22 novembre 1889.

138. Jules Ragot, Notice historique sur la société d'horticulture, suivie du catalogue général des végétaux cultivés dans les jardins de la société. Le Mans, 1902. Notons aussi la publication d'une longue série d'articles sur la flore asiatique, sous la plume d'Hector Léveillé (originaire du Mans, quelque temps missionnaire à Pondichéry de 1887 à 1892 , avant de revenir dans sa ville natale pour raison de santé) dans le Bulletin de la Société d'Agriculture Sciences et Arts de la Sarthe entre 1889 et 1902.

139. Le Petit Manceau, 5 juin 1906.

140. Le Petit Manceau, 22-23 mars 1914.

141. Le Petit Manceau, 28 septembre 1911 et Archives municipales du Mans, Ø 946. 
oublier un grand dragon de dix mètres de long qui crache des flammes ${ }^{142}$. Le soir, un feu d'artifice " sino-japonais " clôture dignement la fête ${ }^{143}$. La cavalcade confirme l'intérêt pour l'Asie, une Asie de rêve et d'exotisme ${ }^{144}$ dont on ne considère que le passé; ainsi qu'une hiérarchisation de ces peuples au profit quasiment exclusif du Japon.

\section{La mobilisation des catholiques en faveur de l'Asie}

Pour les catholiques, l'Asie est souvent perçue comme le lieu des persécutions les plus affreuses. Depuis son premier numéro paru en novembre 1862, jusqu'en 1914, La Semaine du Fidèle a consacré un minimum de soixante seize articles à ces épisodes sanglants. Le reste de la presse locale, quoique moins concerné, y a fait trente fois référence (dans le cadre des divers sondages réalisés). Autant d'allusions qui renforcent l'image de violence des sociétés du continent, déjà relevée précédemment.

Le lieu habituel de la persécution se situe en Chine ou en Indochine ${ }^{145}$ dont les autorités se montrent souvent bienveillantes pour les persécuteurs quand elles ne les encouragent pas ouvertement. En 1866, le diocèse du Mans s'enorgueillit de donner un martyr à l'Église en la personne de Siméon Berneux, vicaire apostolique en Corée. La nouvelle de sa mort suscite l'émotion mais aussi la ferveur parmi les fidèles et plus encore dans le clergé dont beaucoup de membres ont connu le confesseur de la Foi au début de sa carrière ecclésiastique dans la Sarthe ${ }^{146}$. Cette réalité sanglante est bien loin de décourager les bonnes volontés comme l'atteste le succès de La Sainte Enfance ${ }^{147}$, œuvre qui a pour but de «sauver les pauvres petits enfants païens de la Chine que l'on expose aux bêtes et aux flots, et de leur procurer le bienfait du saint baptême, puis, quand on le peut, de les élever dans les orphelinats des missionnaires ${ }^{148} "$.

142. Le Petit Manceau 16 et 28 septembre 1911. Gaëlle Leveau, L'Exposition du Mans de 1911 en Histoire et en images, mémoire de maîtrise sous la direction de Brigitte Waché et Annie Duprat, Université du Maine, septembre 1999, p. 64-69, documents 47 à 55.

143. En hommage à la maîtrise pyrotechnique du Pays du Soleil Levant, on y admire un " dragon de feu ", " la gloire du Mikado ", les " cascades du Fuji-Yama " et un "Japonais de feu ". (Le Nouvelliste de la Sarthe, $1^{\mathrm{er}}$ et 2 octobre 1911).

144. L'année précédente, le public manceau avait pu applaudir le char de la reine des fleurs japonaises, " avec ses mignonnes japonaises [...], ces jolies fleurs vivantes que Loti a exaltées "; allusion à Madame Chrysanthème et à Japoneries d'automne publiées en 1887 et 1889. (Le Petit Manceau, 13 juin 1910).

145. Même en Inde, les catholiques ne sont pas toujours à l'abri des violences; mais il s'agit ici d'agressions de la part de leurs voisins hindouistes ou musulmans (Lettre du RP Vérité, publiée dans La Chronique de l'Ouest, 1857, p. 488).

146. Lettre pastorale de $\mathrm{M}^{\mathrm{gr}}$ Fillion sur le martyr de $\mathrm{M}^{\mathrm{gr}}$ Berneux, datée du 14 septembre 1867, (Archives diocésaines du Mans).

147. La Sainte Enfance, créée en 1843 par M ${ }^{\mathrm{gr}}$ Forbin Janson, évêque de Nancy, n'a été reçue dans le diocèse du Mans qu'en avril 1851.

148. Circulaire de $\mathrm{M}^{\mathrm{gr}}$ Bouvier " pour recommander la Propagation de la Foi et régler l'œuvre de La Sainte Enfance dans le diocèse ", 5 avril 1851. Plus loin, l'évêque évoque ces " enfants dont on craint d'être embarrassés par la suite [traités] absolument comme dans 
Au Mans même, La Sainte Enfance prend des allures de mouvement de masse. Entre les années 1860 et 1880, elle parvient à mobiliser jusqu'à 4000 à 5000 enfants, phénomène tout à fait remarquable dans une ville dont la population progresse alors de 40000 à 55000 habitants ${ }^{149}$. Ses fêtes annuelles qui mettent en mouvement dans les rues des milliers d'enfants derrière des bannières et des oriflammes, au son des fanfares, convergeant de leurs paroisses respectives vers la cathédrale, où l'évêque vient présider une messe solennelle, apparaissent comme autant d'occasions d'attirer l'attention de tous sur la Chine et d'intéresser nombre de parents aux objectifs de l'œuvre ${ }^{150}$.

Les ressources mobilisées annuellement ne sont pas négligeables ${ }^{151}$. De près de $9000 \mathrm{~F}$ vers 1860, elles progressent jusqu'à la fin des années 1870 avec plus de $17000 \mathrm{~F}$ en 1878 ; la tendance se retrouve alors, non sans quelques sursauts, et la somme recueillie ne dépasse guère les $7000 \mathrm{~F}$ à la veille de 1914 (voir diagramme en annexe). Ce recul s'explique par un faisceau de causes, du déclin de la présence des religieuses dans les écoles (conséquence de l'application des lois Ferry) au développement de nouvelles sollicitations missionnaires, notamment au profit des populations d'Afrique Noire, ainsi qu'à l'émergence de nouveaux besoins pour l'Église locale (œuvres de jeunesse, bonne presse, nécessaire compensation des conséquences matérielles de la loi de séparation). L'hostilité de nombreux républicains ne facilite pas les choses, soit qu'ils dénoncent un "infanticide " chinois inventé par le clergé pour soutirer de l'argent (dans quel but?) aux naïfs ${ }^{152}$, soit qu'ils s'interrogent sur une charité lointaine qui ferait mieux de s'intéresser aux enfants pauvres de chez nous ${ }^{153}$.

Pour les catholiques adultes, le contact avec les réalités asiatiques ne s'opère pas seulement à travers la lecture édifiante des Annales de la Propagation de la Foi mais également par le contact direct avec des missionnaires, dont rend compte La Semaine du Fidèle. C'est ainsi que l'on constate la présence au Mans de $\mathrm{M}^{\mathrm{gr}}$ Sohier, vicaire apostolique de

nos pays civilisés nous traitons les animaux domestiques qui naissent en trop grand nombre pour être tous élevés et ces parents chinois avides d'argent et très pauvres [qui] cèdent volontiers, pour quelques pièces de monnaie, ces infortunés enfants ".

149. Estimations à partir des informations publiées par La Semaine du Fidèle du 23 avril 1881. Pour l'ensemble du département, l'effectif pouvait être de l'ordre de 20000 membres.

150. On peut retrouver la description de ces fêtes dans La Semaine du Fidèle : 19 janvier $1860 ; 19$ décembre $1868 ; 22$ février 1873 ; 5 février $1876 ; 22$ janvier $1881 \ldots$

151. Statistique établie à partir des informations de La Semaine du Fidèle et des comptes imprimés de l'œuvre (Arch. dép. de la Sarthe : 13F630). À titre de comparaison, en 1880, " l'œuvre des campagnes" qui vient en aide aux paroisses françaises dans le besoin, a recueilli 1363 francs (Semaine du Fidèle, 25 mai 1881).

152. La Semaine du Fidèle du 15 janvier 1876 rappelle que la justice a condamné Edmond About et Francisque Sarcey, rédacteurs du " Dix neuvième siècle " pour diffamation à ce sujet, ce qui n'empêche pas L'Avenir de la Sarthe des 26-27 février 1877 de continuer de mettre en doute ce recours à l'infanticide.

153. Le Petit Manceau du 2 décembre 1889 qui, sous le titre "Pour les petits chinois, s’il vous plait?" s'interroge : "N'y a-t'il pas assez d'enfants pauvres au Mans? " 
Cochinchine septentrionale, à Noël 1864; après avoir officié au Grand Séminaire dont il fut l'élève, il prend la parole devant les fidèles de la plus grande paroisse de la ville, qui se montrent généreux pour sa chrétienté ${ }^{154}$. À l'occasion des fêtes organisées pour exalter le martyr de $\mathrm{M}^{\mathrm{gr}}$ Berneux, Château-du-Loir, sa ville natale, accueille en 1867, une pléiade d'évêques missionnaires ${ }^{155}$. Deux ans plus tard, revenu du Su Tchuen oriental à l'occasion du Concile, M ${ }^{\text {gr }}$ Pichon officie à la Cathédrale ${ }^{156}$ et en 1874, $\mathrm{M}^{\mathrm{gr}}$ Guillemin, vicaire apostolique de Canton, vient tendre la main pour ériger un séminaire destiné à la formation des prêtres indigènes de sa région ${ }^{157}$.

Après une éclipse de 25 ans, les missionnaires d'Asie font un retour en force avec de nouveaux moyens pour captiver leurs auditoires. Le capucin Bertrand de Dangeul (en 1898) ${ }^{158}$, le RP Capelle (en 1905) ${ }^{159}$ assurent la présentation de leurs missions à l'aide de projections. L'abbé Tournade, en 1906, est accompagné d'un jeune " céleste, petit mandarin fraîchement débarqué de Pékin, qui s'est exprimé en français de façon extraordinaire ${ }^{160}$ ». Mais l'attraction la plus sensationnelle réside dans la venue au Mans de $\mathrm{M}^{\mathrm{gr}}$ Favier, le héros et le rescapé de la révolte des Boxers, dans le cadre de la fête patronale du diocèse, au début de $1901^{161}$.

La Semaine du Fidèle permet aussi d'entretenir un courant d'échanges avec les missionnaires d'origine locale. Elle publie des extraits de lettres adressées à leurs familles, à des ecclésiastiques de leurs amis ou à des religieuses dévouées. Ces lettres donnent des descriptions vivantes de leur vie, de l'environnement matériel et humain dans lequel ils évoluent, de leurs besoins ${ }^{162}$. À travers elles, se trouvent mobilisées les bonnes volontés pour la réalisation de projets précis : édification d'une chapelle ${ }^{163}$, d'une école ${ }^{164}$, d'un hospice de vieillards ${ }^{165}$, d'établissement de couples de paysans catholiques ${ }^{166}$.

154. La Semaine du Fidèle, 24 décembre 1864; 11 mars 1865.

155. Chronique de l'Ouest, 11 et 18 mars 1867 : sont notamment présents $M^{\text {gr }}$ Gaultier, vicaire apostolique du Tonkin méridional, Charbonneau, vicaire apostolique du Mayssour (Inde), Languillat, vicaire apostolique de Nankin, $M^{\text {gr }}$ Dufal, évêque de Dacca, Perny, pro vicaire apostolique du Su Tchuen oriental.

156. La Semaine du Fidèle, novembre-décembre 1869.

157. La Semaine du Fidèle, 6 juin 1874.

158. La Semaine du Fidèle, 6 novembre 1898. Prêtre diocésain en 1885, entré chez les capucins, il a été envoyé en Inde.

159. Le Nouvelliste de La Sarthe, 23 mai et 5 juin 1905.

160. Semaine du Fidèle, 13 avril 1907. Notons que déjà, en 1864, M ${ }^{\text {gr }}$ Sohier était venu au Mans en compagnie d'un prêtre et d'un diacre annamites (La Semaine du Fidèle, 24 décembre 1864). 161. Semaine du Fidèle, $1^{\mathrm{er}}$ février 1901.

162. Ainsi, le RP Langlais présente-t-il les coutumes chinoises (La Semaine du Fidèle des 13 décembre 1873 et 10 janvier 1874) et le RP Grémillon, le travail et la nature du même pays (Semaine du Fidèle, 2 janvier 1886); le Père Furet décrit la fête des morts, au Japon (Semaine du Fidèle, 31 août 1867) etc.

163. Après le passage d'un typhon, en Inde (La Semaine du Fidèle, 24 septembre 1864). 164. La Semaine du Fidèle, 19 janvier 1884; il s'agit d'établir une école professionnelle au Japon. 165. La Semaine du Fidèle, 5 juin 1886; demande du RP Grémillon, pour un village chinois. 166. La Semaine du Fidèle, 7 mars 1902; lettre du RP Deniau, pour l'Inde, l'Hebdomadaire avait présenté le 26 janvier 1878, une demande pour aider des agriculteurs indiens à acquérir des bœufs. 
D'octobre 1877 à septembre 1881, notre modeste hebdomadaire s'associe à un projet beaucoup plus vaste destiné à recueillir des fonds pour porter secours aux populations de l'Inde, touchées par une terrible famine et qui s'étend ensuite à tout l'est du continent. Appuyée sur les témoignages terribles des missionnaires manceaux engagés à travers toute la région, la souscription qui a mobilisé pensionnats, écoles et paroisses (plus du tiers d'entre elles, bonnes et moins bonnes, ont apporté leur contribution) permet de recueillir $20000 \mathrm{~F}$ au moins ${ }^{167}$, un montant très remarquable quand on le rapproche de celui qui fut recueilli pour Pie IX à l'occasion de son jubilé en 1869 : $13690 \mathrm{~F}$; ou de celle qui sera destinée un peu plus tard à venir au secours des "inondés de la Sarthe" (11800 F en 1889) ${ }^{168}$.

Pour les catholiques sarthoises, l'image de ces populations ne se résume donc pas à des coutumes barbares, à des croyances dévoyées ou au martyr infligé à nos missionnaires. Mieux connues, elles méritent qu'on leur vienne en aide. Elles peuvent même devenir des modèles pour la foi. Ainsi, ce maréchal-ferrant tué en Mandchourie pour avoir refusé de prêter son concours à la construction d'un temple païen. "Quelle différence, écrit La Semaine du Fidèle, entre cette conduite héroïque et celle d'un si grand nombre de chrétiens faibles et lâches en face du devoir; quelle différence surtout avec celle de ces crocheteurs de couvents qui acceptèrent sans résistance aucune la triste mission que leur était confiée ${ }^{169}$ " ou encore cette " chrétienté fervente [qui] s'est maintenue 200 ans au Japon, sans culte, sans prêtre, tandis que nous voyons dépérir nos populations "gâtées" de sacrements et de dévotions ${ }^{170 " .}$

\section{L'Asie, pourvoyeuse d'arguments, dans les disputes franco-françaises}

\section{Sa place dans la lutte anti-religieuse...}

La presse d'inspiration monarchiste rend constamment hommage aux missionnaires car c'est leur sang qui « a le premier ouvert à la civilisation occidentale les portes de l'Extrême-Orient ${ }^{171}$ ". Elle souligne les effets bénéfiques de leur action pour notre Pays. "Jusqu'à la veille de l'insurrection des Boxers, remarque le Nouvelliste, il y avait en Chine environ 700000 catholiques. Qui donc gagne à la civilisation, qui donc convertit à l'influence française tant d'êtres humains? Les missionnaires ${ }^{172}$."

167. La ville de La Flèche se distingue lors de cette souscription en y contribuant pour 1108 F. Cette mobilisation doit être mise en relation avec la présence du Prytanée Militaire, dont certains cadres ont servi en Asie tandis que les élèves se montrant sensibles au souvenir des anciens. Cet intérêt déborde sur la ville par l'intermédiaire des élèves externes, et depuis 1860, la présence de nombreux militaires retraités.

168. La Semaine du Fidèle, $1^{\mathrm{er}}$ mai 1869 et 17 août 1889.

169. 9 avril 1881.

170. Archives diocésaines. Dossiers de $\mathrm{M}^{\mathrm{gr}}$ De Bonfils : rapport de l'Abbé Laude, L'action ecclésiastique sous le régime de la séparation, 1906.

171. Chronique de l'Ouest, 7 janvier 1867.

172. Le Nouvelliste de La Sarthe, 26 janvier 1901. Une partie de l'opinion publique est 
Les radicaux dénoncent au contraire " une collision incompréhensible et fatale", car ces " missionnaires catholiques romains poussent la France en avant pour leur profit exclusif. Constamment, notre pays est intervenu par la menace des armes au profit de la propagande des congrégations [...] ayant pour but de convertir les fidèles de Confucius aux beautés du confessionnal jésuitique ${ }^{173}$ ». En 1910, s'appuyant sur le rapport Messimy, Le Petit Manceau dénonce même les "menées des prêtres catholiques annamites qui sapent l'autorité de la France " en Indochine ${ }^{174}$. La Semaine du Fidèle reste très vague en ce qui concerne les religions asiatiques et leur contenu; elle n'accorde une certaine attention qu'au culte des ancêtres où elle voit quelque analogie avec le souvenir de nos propres défunts et un hommage à l'idée de l'immortalité.

C'est paradoxalement la libre pensée qui fait découvrir aux Sarthois les religions orientales. Elles lui permettent de mettre en évidence des convergences troublantes entre la biographie de Jésus et celle de Bouddha, par exemple ${ }^{175}$, ou entre le dogme chrétien de la Trinité et la triade hindouiste constituée de Brahmâ, Vishnou et Shiva ${ }^{176}$; le catholicisme n'est donc qu'une reprise des fables de l'Extrême-Orient, ce qui ruine sa prétention à être " la Religion ". Quant à la " Révélation, on voit ce qu'elle vaut ${ }^{177}$ ". On peut penser qu'un tel argumentaire n'est pas tout à fait sans conséquence puisque La Semaine du Fidèle éprouve le besoin de recommander par la suite l'ouvrage qu'un professeur de l'Université de Fribourg, Alfred Rousset, consacre aux " religions orientales ${ }^{178}$ ".

Outre la polémique sur l'infanticide en Chine réactivée sporadiquement, on peut aussi renouveler l'argumentaire anti-clérical en l'illustrant de quelques " exemples " extrême-orientaux. En montrant par exemple ces Tibétains se rendant nombreux en pèlerinage à Lhassa pour voir le Dalaïlama, comme les catholiques à Rome s'en vont voir le Pape. Comme ces derniers, ils sont également victimes de "dévots roublards " qui savent tirer parti de leur crédulité; moyennant finance, ils font tourner des " machines à prières "; situation comparable à celle des croyants qui, chez nous, font dire des messes! sans oublier la Sainte Inquisition dont les tortures employées par la justice chinoise, viennent rappeler le souvenir ${ }^{179}$.

sensible à cette image; en témoigne la candidature de l'abbé Leveillé, ex-missionnaire aux Indes « qui revendique hautement l'honneur de porter sa soutane et d'avoir fait connaître le nom de la France, jusqu'en Extrême-Orient ", lors d'une élection municipale partielle, au Mans, contre un prêtre défroqué; il recueille 502 voix contre 380 à son adversaire et permet le triomphe d'un troisième candidat (Arch. nat. F19/5915 - février 1893; Le Petit Manceau du 6-9 février 1893).

173. Le Petit Manceau, 27 octobre 1900, qui reprend un article de Gustave Habbard.

174. 6 janvier 1910 .

175. Le Petit Manceau, 2 et 13 août 1894.

176. Le Petit Manceau, 31 août 1894.

177. Le Petit Manceau, 28 janvier 1905.

178. La Semaine du Fidèle, ${ }^{\mathrm{er}}$ octobre 1910 et 28 octobre 1911.

179. Le Petit Manceau, 4 août 1900. 


\section{... et dans les batailles politiques, de "Ferry-Tonkin" et de la construction européenne à l'arbitrage international}

Au cours des années 1880, l'intervention française au Tonkin alimente le débat politique national. L'avenir, organe des républicains opportunistes locaux, reprend à son compte la série des arguments habituels pour justifier les choix de J. Ferry, " obligé " d'intervenir pour ne pas rendre inutiles les sacrifices consentis depuis le Second Empire ${ }^{180}$. Les richesses de Tonkin ${ }^{181}$, sa vocation comme voie d'accès vers la Chine du Sud ${ }^{182}$, les exigences de l'honneur national ${ }^{183}$ sont, tour à tour, invoquées.

Les radicaux dans Le Progrès Républicain ou Le Petit Manceau, et les monarchistes à travers L'Union se retrouvent au contraire pour dénoncer le coût financier et humain de cet engagement ${ }^{184}$, mais alors que les premiers, dénonçant au passage la collusion des intérêts catholiques et opportunistes ${ }^{185}$, concluent à un nécessaire retrait, L'Union s'indigne des tergiversations gouvernementales, d'une politique qui n'ose pas avouer ses objectifs, lésine sur les moyens et expose ainsi soldats et missionnaires à des risques inutiles ${ }^{186}$.

Une solidarité patriotique, non exempte d'arrière-pensées, s'organise pour soutenir les combattants et rendre hommage à leur courage; collectes et concerts au profit des blessés du Tonkin sont signalés par la presse en 1884-1885 ${ }^{187}$. C'est aussi le moment où le Conseil Municipal du Mans attribue à une rue de la ville le nom du Sergent Bobillot, mort des blessures reçues au siège hérö̈que, soutenu à Tuyen-Quan ${ }^{188}$. La mémoire des héros est entretenue par la mode enfantine ${ }^{189}$, les jeux ${ }^{190}$, voire des objets plus inattendus ${ }^{191}$.

Au début du xx $x^{\mathrm{e}}$ siècle, les polémiques politiques se sont déplacées. Elles tournent maintenant autour de la Chine et de son avenir. Le départe-

180. L'Avenir, 9 septembre 1889.

181. L'Avenir, 11 février et 25 octobre 1889.

182. L'Avenir, 15 août 1883.

183. L'Avenir, 12 avril 1885.

184. L'Union, 12 mars 1885; Le Progrès Républicain, 4-11 avril 1885.

185. Le Progrès de l'Ouest, 9-16 janvier 1886.

186. L'Union, 22 février et $1^{\text {er }}$ mars 1885 .

187. Ainsi, Le Progrès Républicain des 23-30 mars 1884, 11-18 avril 1885.

188. Archives municipales du Mans (RD 42), compte rendu des délibérations du conseil du 11 décembre 1885. Bobillot n'a aucun lien spécifique avec Le Mans; il apparaît comme l'archétype du soldat qui donne sa vie pour la Patrie. D'autres villes reprennent aussi son nom à l'époque. Voir : La Sabretache-Société d'Études d'Histoire Militaire, n ${ }^{\circ}$ 151, 2002; MEYNIER, Jacques, Le sergent Bobillot à Tuyen-Quan.

189. Dans Le Progrès de l'Ouest des 16-20 juin 1885, la maison de confection Nathan présente, dessin à l'appui, "le Tonkin ", " petit costume marin fantaisie ".

190. L'auteur se souvient d'avoir joué, chez ses grands-parents, avec un puzzle ancien qui représentait des scènes de combat, fourmillant de soldats français, d'annamites et de « pavillons noirs".

191. Ainsi, cette comtoise achetée chez un horloger de La Flèche vers la fin du XIXe siècle, dont le balancier historié et animé met en scène un fantassin et un marin français à l'assaut d'un village indochinois (photo en annexe). 
ment compte alors, parmi ses élus, Paul d'Estournelles de Constant, venu de la diplomatie à la politique; appuyé par les républicains avancés, il se fait remarquer par ses vues d'anticipation. La révolte des Boxers et la mise sur pied, pour l'occasion, d'une force d'intervention internationale, lui permet de développer son point de vue sur la nécessité d'une union européenne (déjà perçue selon lui par l'opinion ${ }^{192}$ ) sous peine d'un suicide pour les pays de notre continent, confronté aux bouleversements du monde ${ }^{193}$. Pendant ce temps, d'autres (les nationalistes du journal La Sarthe) déplorent la trop modeste place de l'armée française dans l'expédition internationale de Chine dont le commandement, ô honte, a été confié au maréchal allemand Waldersee ${ }^{194}$ ! En 1904, le même journal tourne en ridicule ce " diplomate prétentieux "; ce " hanneton du coche " (d'Estournelles) dont les rêves d'arbitrage international des conflits se trouvent battus en brèche à l'occasion de la guerre russo-japonaise ${ }^{195}$; “ Le Hanneton " se voit pourtant attribuer le prix Nobel de la Paix en $1909^{196}$.

L'Asie du Sud et l'Extrême-Orient se sont assurés progressivement une place dans l'environnement quotidien des Sarthois en y apportant une touche de fantaisie et d'exotisme. Pour une élite catholique ainsi que pour de nombreux enfants, ils acquièrent, par l'intermédiaire des missionnaires, une dimension très concrète, leurs populations deviennent l'objet d'une solidarité pratique; elles peuvent même être proposées en modèles pour la Foi. Ces régions fournissent aussi des arguments pour alimenter le conflit religieux qui divise le pays et prennent place dans le débat politique qui agite la France sur les options à prendre à propos de l'Indochine, comme de la Chine. Ainsi, avec une intensité plus ou moins considérable selon les moments et les options politiques et religieuses des uns et des autres, on constate que la présence de l'Asie s'est imposée à l'esprit des Sarthois.

La presse locale a accordé, à partir de 1844, à une poignée de pays asiatiques, une place modeste qui a assuré, toutefois, leur ancrage dans l'environnement intellectuel des habitants.

La Semaine du Fidèle, s'adressant avant tout à l'élite catholique, est surtout motivée par la présence sur place de missionnaires d'origine locale. Grâce à eux, elle répand une connaissance plus concrète et suscite un intérêt pratique au bénéfice des populations dont les missionnaires se font les

192. Dans une interview au Temps du 7 juillet 1900, repris dans Le Petit Manceau deux jours plus tard, il affirme : "Examinons notre conscience. Le sang allemand, anglais, italien ou russe versé en Chine est à nos yeux, non du sang étranger, mais du sang européen. C'est notre sang ".

193. Le Bonhomme Sarthois, 28 juin 1900; Le Petit Manceau, 9 juillet et 12 novembre 1900 ; Le Progrès Républicain, 18 novembre 1900.

194. La Sarthe, 30 juin, 24 et 27 août 1900.

195. La Sarthe, 10-16 février 1904. Le 19 février 1904, à l'occasion du Congrès de La Haye, le journal titre sur " un apôtre déçu ".

196. Barcelo, Laurent, Paul d'Estournelles de Constant, l'expression d'une idée européenne, Paris, L'Harmattan, 1995. 
médiateurs. C'est une approche originale car le regard porté sur ces pays et leurs habitants par le reste de la presse sarthoise paraît, dans l'ensemble, assez convenu, confortant le sentiment européen de supériorité et justifiant les entreprises de conquête, qu'elles soient militaire, commerciale ou religieuse.

Le Japon, seul, échappe à ce regard arrogant tandis qu'avec le temps, l'image de la Chine se fait moins simpliste. La découverte des arts extrêmeorientaux soutenue par le goût de l'exotisme, suscite l'intérêt, ouvre la voie à un regard moins " eurocentrique " alors que les arguments des disputes politico-religieuses empruntés aux réalités asiatiques, conservent, quant à eux, un caractère des plus superficiel. Au début du xx siècle, la défiance s'impose : le Japon, trop bon élève de l'Occident, suscite maintenant l'inquiétude. La violence xénophobe des chinois portée à son paroxysme et très médiatisée, à l'occasion de la révolte des Boxers, annonce une évolution incontrôlable de ses foules innombrables. Quant aux catholiques, ils voient leurs espoirs de conversions massives frustrés ${ }^{197}$ alors que le nombre des missionnaires sarthois engagés sur le terrain décline rapidement, rompant les liens ténus, tissés avec quelques populations asiatiques témoins. Les Sarthois semblent à la veille de perdre leurs illusions sur l'Extrême-Orient et de s'en détourner.

197. Il paraît alors loin le temps où La Chronique de l'Ouest écrivait - le 17 août 1859 " le plus grand Empire de la terre s'avance à pas lents mais sûrs dans les voies du Catholicisme " et où La Semaine du Fidèle annonçait - le 11 juin 1864 - « de consolantes nouvelles sur l'avenir de la religion catholique au Japon ". 
Cette étonnante illustration de la conquête du Tonkin ornant le balancier d'une comtoise, choisit de donner la place d'honneur au redoutable pavillon noir défendant son village (pour mieux mettre en évidence le courage du soldat et du marin français, apparaissant tour $\grave{a}$ tour dans les échancrures de la palissade?) (coll. part.)

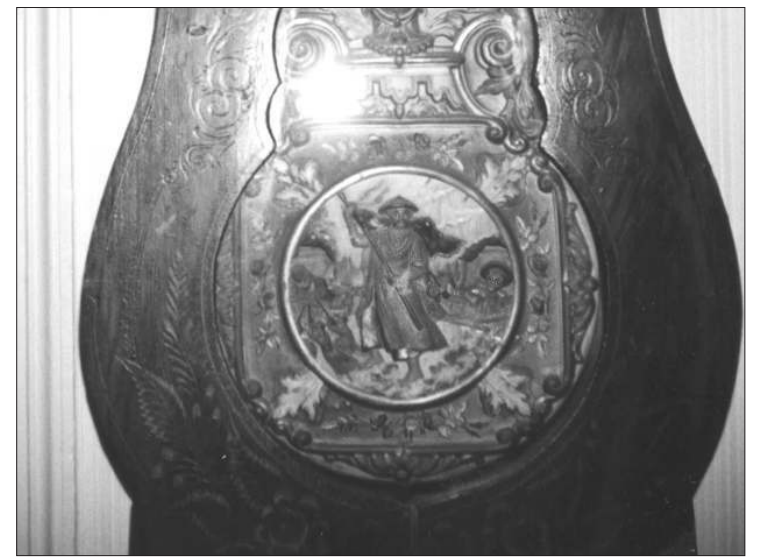

Entre le milieu et la fin du siècle, par l'intermédiaire de ses images, la Sainte-Enfance fait glisser le regard de ses membres de la France et de son clergé vers la Chine et ses habitants même si l'évocation en reste très convenue
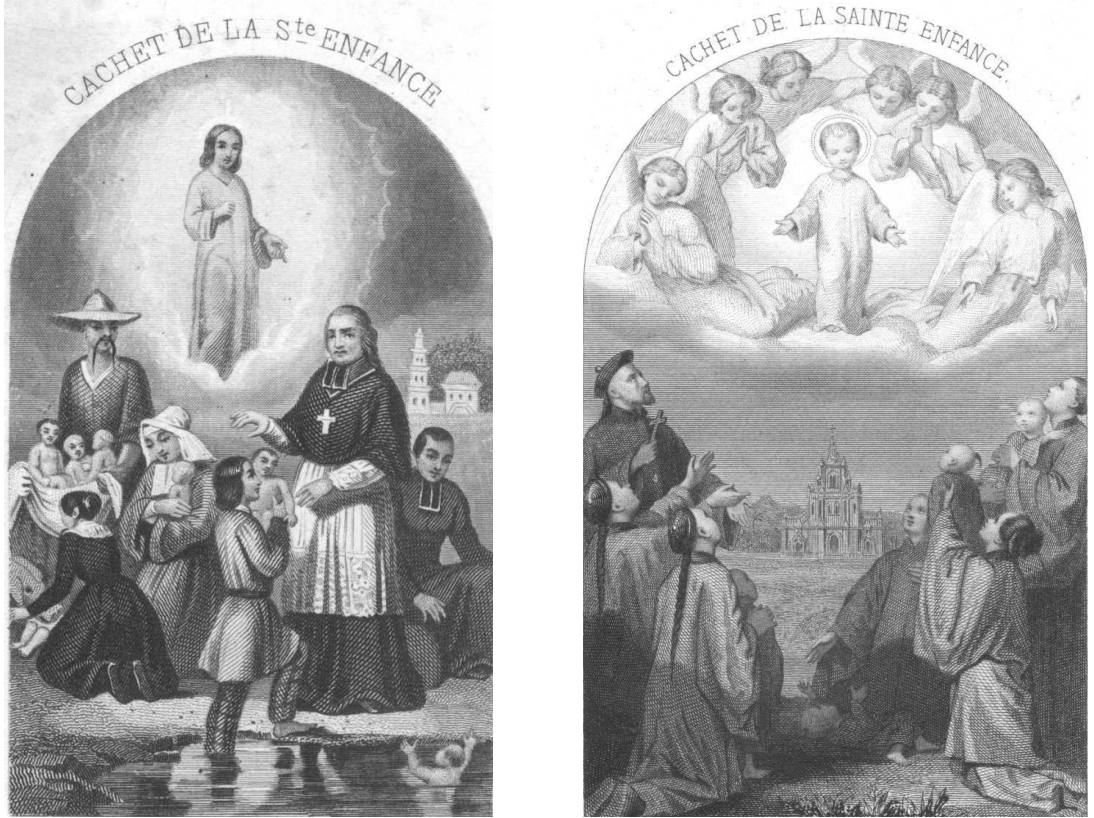


\section{RÉSUMÉ}

Quelle image les Sarthois se font-ils des pays qui s'étendent de l'Inde jusqu'aux extrémités orientales du continent asiatique dans la période 18601914 ? Font-ils entrer dans leur vie des réalités asiatiques? L'étude de la presse locale permettra de répondre à ces deux questions. Le pays le plus cité est la Chine, suivie de l'Indochine; le Japon et l'Inde sont très en retrait. L'image de ces pays est ambivalente : d'une part des pays de cocagne qui regorgent de richesses de toutes sortes, de l'autre des terres de catastrophes et de mort. Ce sont aussi des sociétés impitoyables et sont évoqués les supplices, les suicides rituels, les violences physiques et morales faites aux femmes chinoises et hindoues. La vision des Chinois oscille entre mépris et admiration. Le Japon, au moment où il entre dans l'ère Meiji, fait l'objet de tous les éloges; ses victoires militaires sur la Chine puis sur la Russie ne sont pas étrangères à cette image. Si la place des objets asiatiques est peu importante dans les intérieurs sarthois, en revanche, la mobilisation des catholiques sarthois est importante en leur faveur.

\section{ABSTRACT}

What did people from la Sarthe think of all the countries located between India and the extreme east of the Asian continent between 1860 and 1914? Is Asian culture really part of their lives?

We can find the answers to these two questions by studying local newspapers.

The country written about the most is China followed by Indonesia; with Japan and India far behind them.

The image given of these countries is rather contradictory: on the one hand they were portrayed as the land of plenty with an abundance of wealth of all kinds, but on the other hand they were described as lands of death and catastrophe. They were also ruthless societies where torture and ritual suicides were said to be commonplace and where Hindu and Chinese women were physically and morally abused. Chinese people are viewed with both despise and admiration. Japan was entering the Meiji era and was highly praised, mostly for her military victories over China and then Russia. Even if Asian objects were rarely to be seen in the home of Sarthe inhabitants, the Catholics from La Sarthe supported them vigorously. 